\title{
Towards the Large-Scale Electrochemical Reduction of Carbon Dioxide
}

\author{
Subin Park ${ }^{1,+}$, Devina Thasia Wijaya ${ }^{2,+}{ }^{\mathbb{D}}$, Jonggeol Na ${ }^{1,3, *}$ and Chan Woo Lee ${ }^{2, * \mathbb{D}}$ \\ 1 Department of Chemical Engineering and Materials Science, Ewha Womans University, Seoul 03760, Korea; \\ psb9352@ewhain.net \\ 2 Department of Chemistry, Kookmin University, Seoul 02707, Korea; devina21@koomin.ac.kr \\ 3 Department of Chemical Engineering and Materials Science, Graduate Program in System Health Science and \\ Engineering, Ewha Womans University, Seoul 03760, Korea \\ * Correspondence: jgna@ewha.ac.kr (J.N.); cwlee1@kookmin.ac.kr (C.W.L.); Tel.: +82-2-3277-4202 (J.N.); \\ +82-2-910-4733 (C.W.L.) \\ + These authors contributed equally to this work.
}

Citation: Park, S.; Wijaya, D.T.; Na, J.; Lee, C.W. Towards the Large-Scale Electrochemical Reduction of Carbon Dioxide. Catalysts 2021, 11, 253. https://doi.org/10.3390/ catal11020253

Academic Editor: Wei An

Received: 25 January 2021

Accepted: 9 February 2021

Published: 13 February 2021

Publisher's Note: MDPI stays neutral with regard to jurisdictional claims in published maps and institutional affiliations.

Copyright: (c) 2021 by the authors. Licensee MDPI, Basel, Switzerland. This article is an open access article distributed under the terms and conditions of the Creative Commons Attribution (CC BY) license (https:/ / creativecommons.org/licenses/by/ $4.0 /)$.

\begin{abstract}
The severe increase in the $\mathrm{CO}_{2}$ concentration is a causative factor of global warming, which accelerates the destruction of ecosystems. The massive utilization of $\mathrm{CO}_{2}$ for value-added chemical production is a key to commercialization to guarantee both economic feasibility and negative carbon emission. Although the electrochemical reduction of $\mathrm{CO}_{2}$ is one of the most promising technologies, there are remaining challenges for large-scale production. Herein, an overview of these limitations is provided in terms of devices, processes, and catalysts. Further, the economic feasibility of the technology is described in terms of individual processes such as reactions and separation. Additionally, for the practical implementation of the electrochemical $\mathrm{CO}_{2}$ conversion technology, stable electrocatalytic performances need to be addressed in terms of current density, Faradaic efficiency, and overpotential. Hence, the present review also covers the known degradation behaviors and mechanisms of electrocatalysts and electrodes during electrolysis. Furthermore, strategic approaches for overcoming the stability issues are introduced based on recent reports from various research areas involved in the electrocatalytic conversion.
\end{abstract}

Keywords: electrochemical reduction of carbon dioxide; process systems; stability; techno-economic analysis; commercialization; large-scale production

\section{Introduction}

In the last few decades, as the world population has increased, severe anthropogenic $\mathrm{CO}_{2}$ emission has become increasingly problematic [1]. The electrochemical conversion of $\mathrm{CO}_{2}$ constitutes a remarkable strategy for enabling negative carbon emission into the atmosphere, as it enables $\mathrm{CO}_{2}$ to be continuously converted into certain value-added chemicals. In addition, when a renewable energy source is used in the conversion, the carbon cycle can be eventually closed, thus providing potential substitutes for fossil fuels in the form of energy storage such as formate, methane, ethylene, $\mathrm{CO}$, methanol, and acetone [2-5]. Moreover, in a large-scale operation, the production of these valued chemicals may satisfy the economic requirements and thus guarantee the sustainability of the technology. The versatility, energy efficiency, and cost-effectiveness of electrochemical $\mathrm{CO}_{2}$ reduction make this one of the most promising technologies not only for mitigating excessive $\mathrm{CO}_{2}$ emission [6] but also for providing an economically viable option in terms of the sustainable carbon cycle, capture, and utilization [7].

Various studies have examined whether electrochemical $\mathrm{CO}_{2}$ reduction technology can achieve an economic impact. These studies were based on techno-economic analyses beginning with $\mathrm{CO}$, which is the easiest to make, followed by formic acid, which is considered to have the best economic efficiency. Moreover, recent studies have focused on analyzing 
various $\mathrm{C}_{2+}$ substances [8-10] and coproduction, replacing oxidation at the anode with a useful organic oxidation reaction and thus increasing the economic feasibility [7,11]. Although various economic evaluations are presently being performed on pilot-scale plants, very few cases have actually been demonstrated at that scale. Nevertheless, some actual construction cases have been recently announced at the pilot level [12]. This change in trend can be attributed to the following two technological advances: (i) the emergence of gas diffusion electrode (GDE)-based devices and (ii) pilot-scale studies at the level of process optimization beyond the catalyst or device level [13]. This change is driven by the simultaneous optimization of mass transport and reaction kinetics through device engineering that uses the GDE to solve the low solubility of $\mathrm{CO}_{2}$, maximize the reaction rate in the catalyst layer, and control the rate of proton supply through the membrane. In addition, the amount of electrolyte used can be controlled by modifying the device type to eliminate the need for a separate system. With respect to process scale, conceptual designs of the commercial-scale electrochemical $\mathrm{CO}_{2}$ reduction processes have been studied to estimate the capital and operating costs of each process system. It is this estimate of economic feasibility that promotes actual investment from the industrial or governmental sectors.

Furthermore, securing long-term stability is a prerequisite for the operation of a commercial process. The decreases in electrocatalytic activity and product selectivity have been observed in previous studies and need to be fully understood and resolved to enable the practical implementation of $\mathrm{CO}_{2}$ reduction technologies. The stability issue basically arise from spontaneous dynamic changes in the material properties (e.g., morphology, crystallinity, composition, and valency state) of the electrocatalysts during the $\mathrm{CO}_{2}$ reduction reactions. In addition, the accumulation of undesirable reaction intermediates at the catalyst surface is known to block the active sites for $\mathrm{CO}_{2}$ reduction and intensify the main competing reaction (hydrogen evolution), thus leading to continuous decrease inactivity. Furthermore, as three-phase boundary electrodes have been proven to be critical for upgrading current densities due to the order-of-magnitude higher local concentration of $\mathrm{CO}_{2}$, electrolyte flooding at the interface between gas, liquid, and solid phases has been identified as one of the key degradation mechanisms that impede electrode durability.

Herein, an extensive review is conducted on strategies for the large-scale electrochemical reduction of $\mathrm{CO}_{2}$ and the design of a more robust $\mathrm{CO}_{2}$-reduction process. At the device level, methods for realizing mass production are discussed in-depth with regard to the device type and membrane. At the process level, the construction of an actual commercial-scale plant is discussed in order to intensively illuminate the conceptual design of the entire process, including the separation process. In addition, the economic feasibility is summarized according to the energy source used. Finally, strategies that are beneficial for extending the lifetime of the electrochemical process and achieving an effective and efficient electrochemical $\mathrm{CO}_{2}$ conversion system are discussed.

\section{Current Challenges in the Large-Scale Electrochemical $\mathrm{CO}_{2}$ Conversion Process}

\subsection{Problems at the Device Level}

\subsubsection{Low Current Density}

The challenges for the commercialization of the $\mathrm{CO}_{2}$ electrolyzer is that the current density, energy efficiency, and conversion rate are limited by the poor solubility of $\mathrm{CO}_{2}$ in aqueous electrolytes ( 34 $\mathrm{mM}$ at $298 \mathrm{~K})$ [14-16]. In particular, the rate of $\mathrm{CO}_{2}$ transfer from the bulk electrolyte to the surface of the planer or porous electrode in the batchtype $\mathrm{H}$-cell is limited at high current densities [17]. The solubility of $\mathrm{CO}_{2}$ in this type of cell is especially low in an alkaline electrolyte because any dissolved $\mathrm{CO}_{2}$ is rapidly consumed to form a neutral-pH carbonate mixture [14]. The reaction of $\mathrm{CO}_{2}$ with hydroxide $\left(\mathrm{OH}^{-}\right)$to form carbonate $\left(\mathrm{CO}_{3}{ }^{2-}\right)$ is rapid and thermodynamically favorable based on the chemistry. This is the obstacle to improving the performances, which results in large voltage and $\mathrm{CO}_{2}$ losses. Nevertheless, the $\mathrm{H}$-cell is commonly used in electrochemistry due to its simple configuration of two electrodes immersed in an electrolyte without recycling. Moreover, this clean and easy to operate configuration can be used to rapidly screen various 
catalysts [18]. However, future devices must be stable during long-term operation $(>20,000$ h) at significant current densities $\left(>200 \mathrm{~mA} \mathrm{~cm}^{-2}\right)$ to remain economically attractive [18]. In this respect, the $\mathrm{H}$-cell is not suitable for large-scale applications, and the continuous flow-cells are emerging as alternative devices.

\subsubsection{Electrolyte $\mathrm{pH}$ Management}

Ion exchange membranes are used to prevent reoxidation of the products formed at the cathode and to improve the product separation by avoiding mixing of the gaseous products [19]. However, the internal mass transfer can lead to a $\mathrm{pH}$ gradient across the membrane, thus potentially generating additional resistance and ultimately damaging and lowering the energy efficiency of the system [20]. This problem does not occur under strongly acidic or basic conditions because the current is carried entirely by the migration of the mobile $\mathrm{H}^{+}$and $\mathrm{OH}^{-}$ions, which are present everywhere in high concentration. However, with a catalyst that functions optimally at a neutral to slightly basic $\mathrm{pH}$, e.g., cobalt-phosphate $\left(\mathrm{Co}-\mathrm{P}_{\mathrm{i}}\right)$ and nickel-borate $\left(\mathrm{Ni}-\mathrm{B}_{\mathrm{i}}\right)$, the current is no longer driven by $\mathrm{H}^{+}$and $\mathrm{OH}^{-}$, thus resulting in potential loss [21]. Nevertheless, the Earth abundance of these catalysts leads to lower cost, and they are useful for driving oxygen evolution reactions (OERs) at moderate overpotentials [20]. Therefore, solving the $\mathrm{pH}$ gradient problem could provide additional options when selecting a catalyst and, thus, enhance the economic feasibility. Moreover, the carbon dioxide reduction reaction $\left(\mathrm{CO}_{2} \mathrm{RR}\right)$ and the OER are active under different $\mathrm{pH}$ conditions. However, when using a cation exchange membrane (CEM) or an anion exchange membrane (AEM), it is difficult to achieve the requisite $\mathrm{pH}$ for the anode or cathode. When using a CEM, the anode must operate in an acidic environment, which requires an expensive OER catalyst. For the EM, however, the bicarbonate electrolyte increases the rate of product crossover from cathode to anode, especially for neutral and anionic products such as methanol and formate, thus reducing the anode performance [22]. Moreover, under the high current density required for scaling up, product crossover must be considered as a loss mechanism [23]. In addition, membrane highly affects the lifetime of overall systems. Several studies on the lifetime test of $\mathrm{CO}_{2}$ to $\mathrm{CO}$ was conducted [24-26], and they conducted the experiment to show how long the membrane will hold some hydration for over $4000 \mathrm{~h}$ of operation. The result showed that the stable $3.0 \mathrm{~V}$ cell voltage and almost $90 \% \mathrm{CO}$ selectivity when circulated $10 \mathrm{mM} \mathrm{KHCO}$ solution in the anode. This way membrane would not be hydrated due to the water balance in the membrane. This can also lead to a stable lifetime operation.

\subsection{Problems at the Process Level}

\subsubsection{Product Separation}

The low solubility of $\mathrm{CO}_{2}$ in aqueous-fed systems leads to low conversion and is one of the major obstacles to be overcome for commercialization. This has been demonstrated by L.C. Weng et al. [27], who reported that only $30 \%$ of $\mathrm{CO}_{2}$ consumption could be achieved even when operating at up to $1 \mathrm{~A} \mathrm{~cm}^{-2}$ with a $50 \mathrm{sccm}$ feed flow.

A closely related problem is the cost of separation after conversion has been completed in the electrolyzer. Due to the low conversion rate in the $\mathrm{CO}_{2} \mathrm{RR}$, unreacted $\mathrm{CO}_{2}$ remains in the gaseous product stream, thus requiring a product separation unit. In this respect, pressure swing absorption (PSA) is a commonly used, cost-effective technology for the industrial separation and purification of electrolysis gases, with the $\mathrm{CO}_{2}$ being recycled back to the reactor $[9,28]$. However, the low conversion rate then leads to an increasing amount of unconverted $\mathrm{CO}_{2}$ in the separation/recycling loop, thus increasing the cost of separation and, hence, the size and capital cost of the PSA system [9].

Meanwhile, liquid products are mixed with the liquid electrolyte used in the $\mathrm{H}$-cell and flow cell. The single-pass accumulation of liquid products is typically very small, thus allowing the electrolyte to be recycled until a significant amount of liquid product accumulates and steady-state separation begins. However, a significant accumulation of the product in the electrolyte can negatively impact the electrolyzer performance [9]. For 
example, the formate ions from formic acid products become mixed with other impurity ions from solutes (e.g., $\mathrm{K}^{+}, \mathrm{HCO}_{3}{ }^{-}$), thus requiring additional downstream separation steps to obtain the pure formic acid or formic acid solutions. This is both energy- and cost-intensive [29].

\subsubsection{Electricity Costs}

The cost of electricity is the main factor in operational expenditure $[18,28]$. The impact of electricity was determined by $\mathrm{M}$ Rumayor et al. when evaluating the economic feasibility of the electrochemical reduction of $\mathrm{CO}_{2}$ in formic acid production [30]. Two scenarios, designated $E_{\min -82}$ and $E_{\min -21}$, were considered in which a minimum amount of electric energy was consumed without overvoltage loss. In the $E_{\min -21}$ scenario, the formic acid concentration obtained at the outlet via the electrochemical reaction is $21 \mathrm{wt} \%$. The variable costs of production (VCP), including interest, overhead, supervision, taxes + insurance, operating labor costs, maintenance, water, rivers, and electricity, were investigated under this scenario to find a total VCP of $0.26 € \mathrm{~kg}^{-1}$, with the electricity bill making the largest contribution $\left(0.15 € \mathrm{~kg}^{-1}\right)$ [30]. Thus, even though minimal electrical energy consumption was assumed, a significant amount was consumed in the total VCP, thus demonstrating that a strategy for lowering the electricity cost is needed.

This is further illustrated by the work of Matthew Jouny et al., who developed a techno-economic model for a generalized electrochemical $\mathrm{CO}_{2}$ reduction $\left(\mathrm{eCO}_{2}\right)$ plant to analyze the economic viability of various reduction products [9]. The result of their sensitivity analysis is reproduced in Figure 1 . Here, the price of electricity is seen to be in the top 3 factors influencing process profitability for the majority of products. In particular, a change of just $\$ 0.01 / \mathrm{kW}$ h in the production of $n$-propanol results in a difference in the net present value (NPV) of nearly $\$ 40$ million. These results indicate that the price of electricity is an important factor affecting the NPV and that a commercial $\mathrm{eCO}_{2}$ plant could be built if cheap electricity is continuously supplied.

(a)

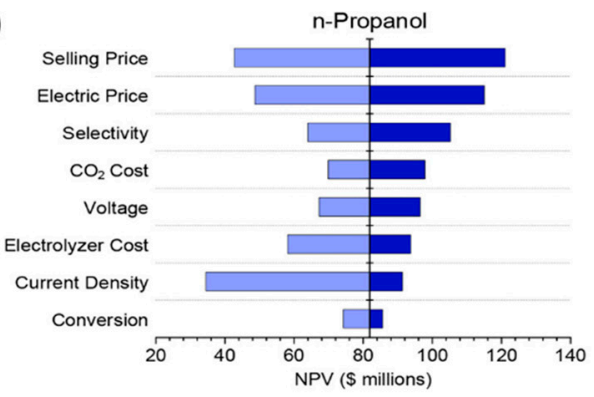

(c)

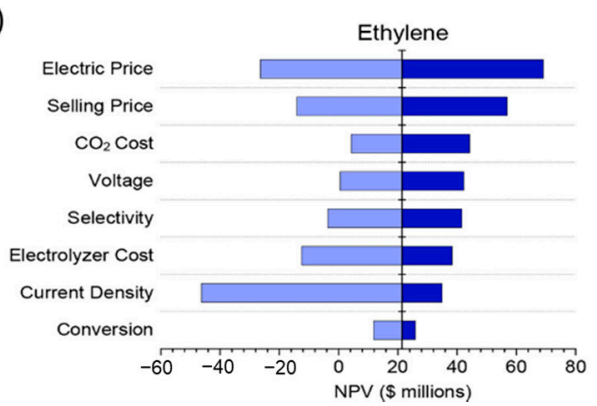

(b)

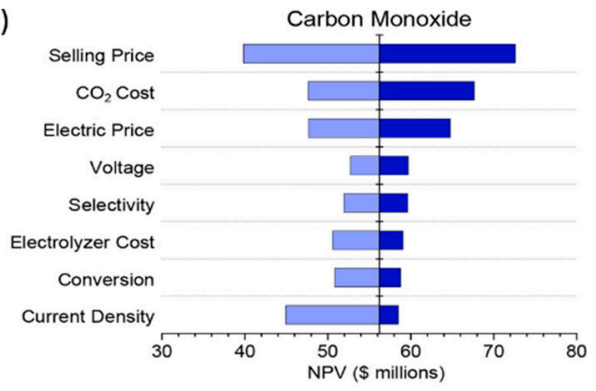

(d)

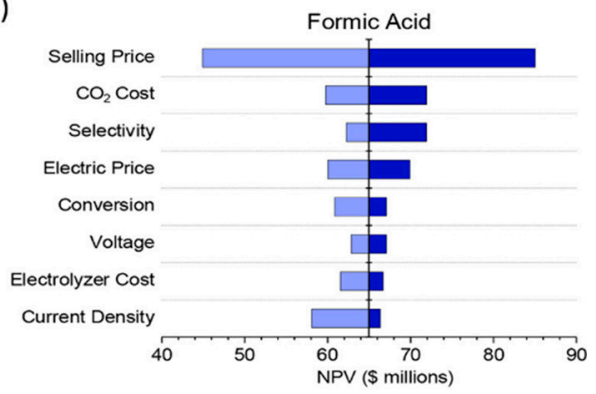

Figure 1. Sensitivity analysis of end-of-life net present value (NPV) for $\mathrm{CO}_{2}$-reduction products: (a) n-propanol, (b) carbon monoxide, (c) ethylene, and (d) formic acid. Adapted from Jouny et al. Reprinted with permission from ref. [9]. Copyright 2018, ACS.

\subsubsection{Integrated Process Design}

Although many researchers are presently working towards the commercialization of $\mathrm{CO}_{2}$ electroreduction by improving the performance of catalyst, device, and process, these 
aspects are generally examined in isolation and are rarely considered all at once. Nevertheless, the various factors are influenced by each other. For example, the composition of products from the electrolyzer will affect the subsequent separation process and ultimately determine the feasibility of the large-scale $\mathrm{CO}_{2}$ electroreduction. Hence, an integrated process design that encompasses every aspect of the $\mathrm{CO}_{2}$ electrochemical system from the small scale (e.g., the catalyst) to the large-scale (e.g., the overall process) is required for the development of a clean electrochemical system to replace petrochemical systems and produce chemicals in an economical and environmentally friendly way.

\section{Cutting Edge Devices for an Electrochemical $\mathrm{CO}_{2}$-Reduction Reactor}

\subsection{The Membrane}

Bipolar membranes (BPMs) are anion and cation exchange membranes that can be combined with a catalyst that promotes the auto dissociation of water at the interface while solving the $\mathrm{pH}$ gradient problem by maintaining a constant $\mathrm{pH}$ at the anode and cathode [22]. The BPM design enables the use of earth-abundant metal anodes that are only stable in basic conditions along with highly active acid-stable cathodes for $\mathrm{CO}_{2}$ reduction [31]. This is because the predominance of $\mathrm{H}^{+}$and $\mathrm{OH}^{-}$species inside the cation exchange layer (CEL) and anion exchange layer (AEL) allows the major charge carriers of the electrolyte to remain constant [20,31]. As shown schematically in Figure 2, this BPM configuration could, in principle, be exploited to sustain a $\mathrm{pH}$ gradient in a water-splitting system [32].

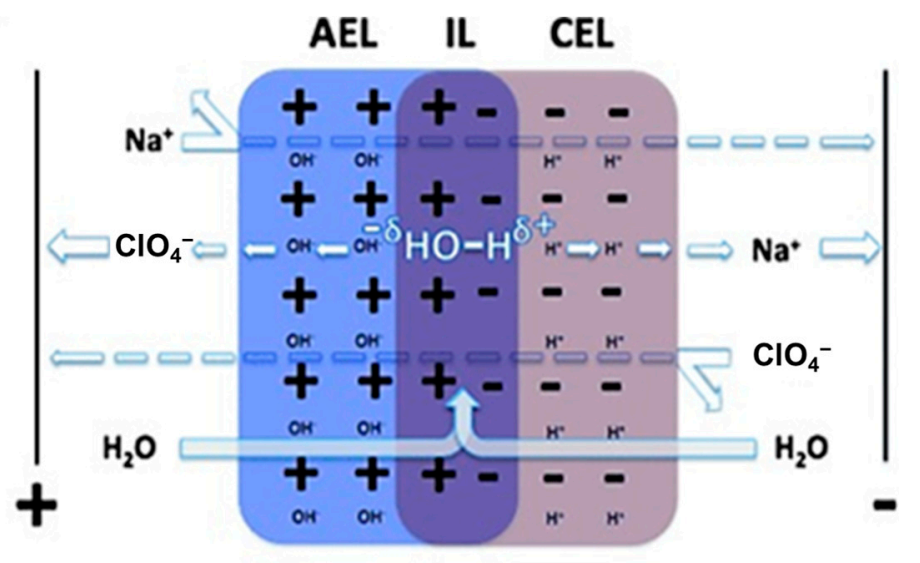

Figure 2. The bipolar membranes (BPM) configuration with base $(1 \mathrm{M} \mathrm{NaOH})$ in the anion exchange layer (AEL) as the anode and acid $\left(1 \mathrm{M} \mathrm{HClO}_{4}\right)$ in the cation exchange layer (CEL) as the cathode. Thus, $\mathrm{OH}^{-}$is consumed at the anode and $\mathrm{H}^{+}$is consumed at the cathode; $\mathrm{Na}^{+}$and $\mathrm{ClO}_{4}{ }^{-}$transport is electrostatically attenuated, and the ionic current is enabled by water dissociation in the interfacial layer. Reproduced with permission from ref. [32]. Copyright 2014, Wiley-VCH.

The conversion of $\mathrm{CO}_{2}$ to $\mathrm{CO}$ was demonstrated by D.A. Salvatore et al. using a modified electrolyzer flow cell in which a solid-supported aqueous layer $\left(1.0 \mathrm{M} \mathrm{NaHCO}_{3}\right)$ was inserted between the silver-based catalyst layer and the bipolar membrane [31]. In addition, the cathode selectivity towards the reduction of $\mathrm{CO}_{2}$ to $\mathrm{CO}$ was improved by the use BPMs. The results indicated a high current density of $200 \mathrm{~mA} \mathrm{~cm}{ }^{-2}$ and stable performance for $24 \mathrm{~h}$. An experiment was also conducted to demonstrate the critical role of hydration on the performance of the solid-supported aqueous layer. When using a low-humidity $\mathrm{CO}_{2}$ inlet, the cell was found to rapidly decay within $2 \mathrm{~h}$, whereas the use of humidified $\mathrm{CO}_{2}$ provided a $65 \%$ Faradaic efficiency (FE) and $100 \mathrm{~mA} \mathrm{~cm}{ }^{-2}$ for $>24 \mathrm{~h}$. These results demonstrated that the BPM-based cell provides sufficient current density for commercialization and that the performance of the cell is influenced by the level of hydration [31]. 
In addition, Y.C. Li et al. compared the crossover properties of AEMs and BPMs to demonstrate that BPMs can inhibit the crossover of both the anionic and neutral products of $\mathrm{CO}_{2}$ electrolysis [23]. The experiments were performed in an $\mathrm{H}$-cell with $0.5 \mathrm{M} \mathrm{KHCO}_{3}$ $(80 \mathrm{~mL})$ as the electrolyte in both the cathode and anode compartments in order to measure the rate of anionic and neutral molecule crossover. In particular, a linear decrease in the concentration of formate by up to $15 \%$ over a period of $4 \mathrm{~h}$ was observed at the cathode with the AEM. At the same time, the concentration of formate at the anode was seen to increase, thus indicating that the formate passed through the membrane to the anode. This was attributed to the similar size of the formate and bicarbonate anions, thus enabling the formate to pass through the AEM by electromigration. By comparison, the crossover rate of formate when using a commercial or 3D BPM under the same conditions was found to be 17 times lower and to further increase with increasing current density [23]. Thus, in view of the high current density requirements of large-scale applications, the BPMs are promising components.

\subsection{The Device}

The continuous flow reactor overcomes the mass transport limitations of the H-cell by circulating the reactants and products away from the electrode [14,33]. Moreover, a further advantage is that the continuous flow reactor overcomes the low solubility of $\mathrm{CO}_{2}$ by using gaseous electrochemical reduction [14]. Thus, several papers have reported a current density of over $200 \mathrm{~mA} \mathrm{~cm}^{-2}$ when using the GDE [34-36]. Hence, the present section is focused on the device configuration and discusses the microfluidic cell, zero-gap electrolyzer, and multilayer electrolyzer stack that make commercialization possible.

\subsubsection{The Microfluidic Cell}

This membrane-less electrolyzer decreases ohmic loss by operating without a physical barrier such as a membrane [18]. The structure of the microfluidic cell relies on the separation of the anode and cathode by appropriately designed, very thin $(<1 \mathrm{~mm})$ channels through which the liquid electrolyte passes in a laminar flow [33]. This eliminates the problems associated with mass transfer and neutralization between the acidic catholyte and alkaline anolyte due to crossover or mixing, which would reduce the concentration of $\mathrm{OH}^{-}$and $\mathrm{H}^{+}$ions and, hence, the current density. Further, in contrast to the membranebased electrochemical system where one electrode is immersed in an acidic medium and another in an alkaline medium, the membrane-less electrolyzer allows the individual compositions of the anolyte and catholyte to be adjusted, thus optimizing the kinetics and thermodynamics at both electrodes and greatly improving the cell performance [37]. For example, the high current density that can be achieved by the microfluidic device has been demonstrated in a study by J. J. Lv et al. on $\mathrm{CO}_{2}$ reduction in a microfluidic electrolysis cell with a nanoporous copper catalyst [38]. This configuration provided a rich supply of $\mathrm{CO}_{2}$ to the catalyst surface at the complex triple-phase boundary, thus enabling the investigation of $\mathrm{CO}_{2}$ electrolysis at high current densities of $>400 \mathrm{~mA} \mathrm{~cm}^{-2}$ at an applied potential of $-0.67 \mathrm{~V}$ (vs. the reversible hydrogen electrode) with a $\mathrm{C}^{2+}$ selectivity of $62 \%$, which is one of the best-reported performances for $\mathrm{CO}_{2}$ electroreduction to $\mathrm{C}^{2+}$ products [38].

Nevertheless, several challenges still exist in microfluidic devices. For instance, the one-channel electrolyte flow design can result in the crossover from cathode to anode [18]. To mitigate this problem, a dual electrolyte system was introduced. For example, $\mathrm{Xu}$ $\mathrm{Lu}$ et al. (2016) reported a dual electrolyte microfluidic reactor (DEMR) that converts $\mathrm{CO}_{2}$ into formic acid with the advantage of $\mathrm{pH}$ optimization for both the anolyte and catholyte (Figure 3) [37]. Thus, at an applied voltage of $2.8 \mathrm{~V}$, the current density was raised significantly from $\sim 10$ to $60 \mathrm{~mA} \mathrm{~cm}-2$ after anolyte optimization (Figure 3a). Moreover, the peak FE was increased from $81.6 \%$ to $95.6 \%$, and the energetic peak efficiency was increased from $41.7 \%$ to $48.5 \%$. Further, a catholyte with a $\mathrm{pH}$ of 2 and an anolyte with a pH of 14 was found to provide the optimal cell performance, thus demonstrating that 
controlling the $\mathrm{pH}$ of the catholyte and anolyte provides a solution for the conversion of $\mathrm{CO}_{2}$ and may eventually facilitate large-scale application [37].
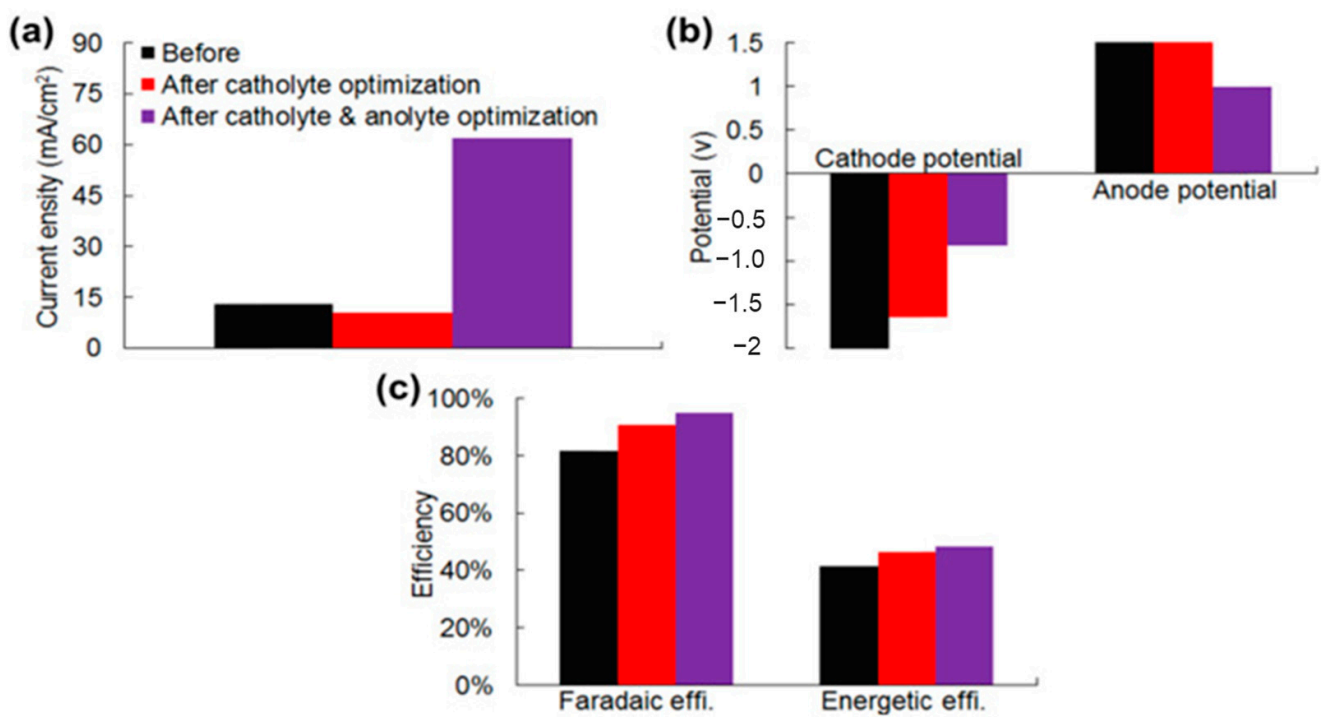

Figure 3. The performance characteristics of the dual electrolyte microfluidic reactor (DEMR): (a) current densities at an applied voltage of $2.8 \mathrm{~V}$ before and after electrolyte optimizations; (b) cathode potentials at $100 \mathrm{~mA} / \mathrm{cm}^{2}$ and catholyte $\mathrm{pH}$ values of 7,1 and 0 , and anode potentials at $150 \mathrm{~mA} / \mathrm{cm}^{2}$ and anolyte $\mathrm{pH}$ values of 7, 13 and 14; (c) peak Faradaic and energy efficiencies before and after electrolyte optimization. Reproduced with permission from ref. [37]. Copyright 2016, Elsevier.

When considering the principle of the dual electrolyte microfluidic cell, the layer thickness between the catholyte and the anolyte is also important because it promotes the neutralization reaction. A significant amount of electrolyte must be used in order to maintain this thickness, which thus weakens the economic benefit. Hence, $\mathrm{Xu} \mathrm{Lu}$ et al. (2017) performed an additional study to identify the operational conditions that allow electrolyte recycling in a microfluidic $\mathrm{pH}$-differential network [39]. The key factors were found to be the electrolyte flow rate (with a threshold value of $500 \mu \mathrm{L} \mathrm{min}{ }^{-1}$ ) and the electrolyte concentration.

\subsubsection{The Zero-Gap Electrolyzer}

Zero-gap electrolyzer cells are present of little interest but could contribute to largescale applications in the future. The main difference between the zero-gap electrolyzer and the flow reactor is the absence of a catholyte flow channel in the former. This is because the configuration can convert $\mathrm{CO}_{2}$ into products without the need for a liquid catholyte, so the cell resistance is very low, and a liquid catholyte circulation loop is not required [40]. Moreover, this minimizes any losses due to the dissolution of $\mathrm{CO}_{2}$ in the catholyte and results in an approximately $50 \%$ decrease in the power required to generate the same amount of $\mathrm{CO}$ with the same family of electrocatalysts as the flow cell [41,42]. This makes the zero-gap electrolyzer a promising configuration.

The two possible flow field patterns of the zero-gap electrolyzer, namely the parallel pattern and the interdigitated pattern, are shown schematically in Figure 4. The performance of each type of zero-gap electrolyzer was compared with that of the well-known catholyte flow-by electrolyzer in a set of experiments by B. D. Mot et al. for $1 \mathrm{~h}$ at $100 \mathrm{~mA}$ $\mathrm{cm}^{-2}$ with a $\mathrm{CO}_{2}$ flow rate of $200 \mathrm{~mL} \mathrm{~min}^{-1}$ and a water injection rate of $0.3 \mathrm{~mL} \mathrm{~min}^{-1}$ into the gas stream [43]. The Faradaic efficiencies (FE) of formate, $\mathrm{H}_{2}$ and $\mathrm{CO}$ production in the catholyte flow-by, parallel pattern and interdigitated pattern, were found to be $67 \%, 43 \%$, and $81 \%$, respectively. Thus, while the parallel flow pattern zero-gap electrolyzer was less efficient than the catholyte flow-by electrolyzer, the interdigitated flow pattern zero-gap 
electrolyzer was significantly more efficient. This is because the interdigitated flow channel forces the $\mathrm{CO}_{2}$ into the GDE, so that mass transfer towards the catalyst surface occurs as a combination of diffusion and convection. Moreover, water was also pushed towards the GDE, thus providing more effective humidification of the membrane electrode assembly (MEA) [43].

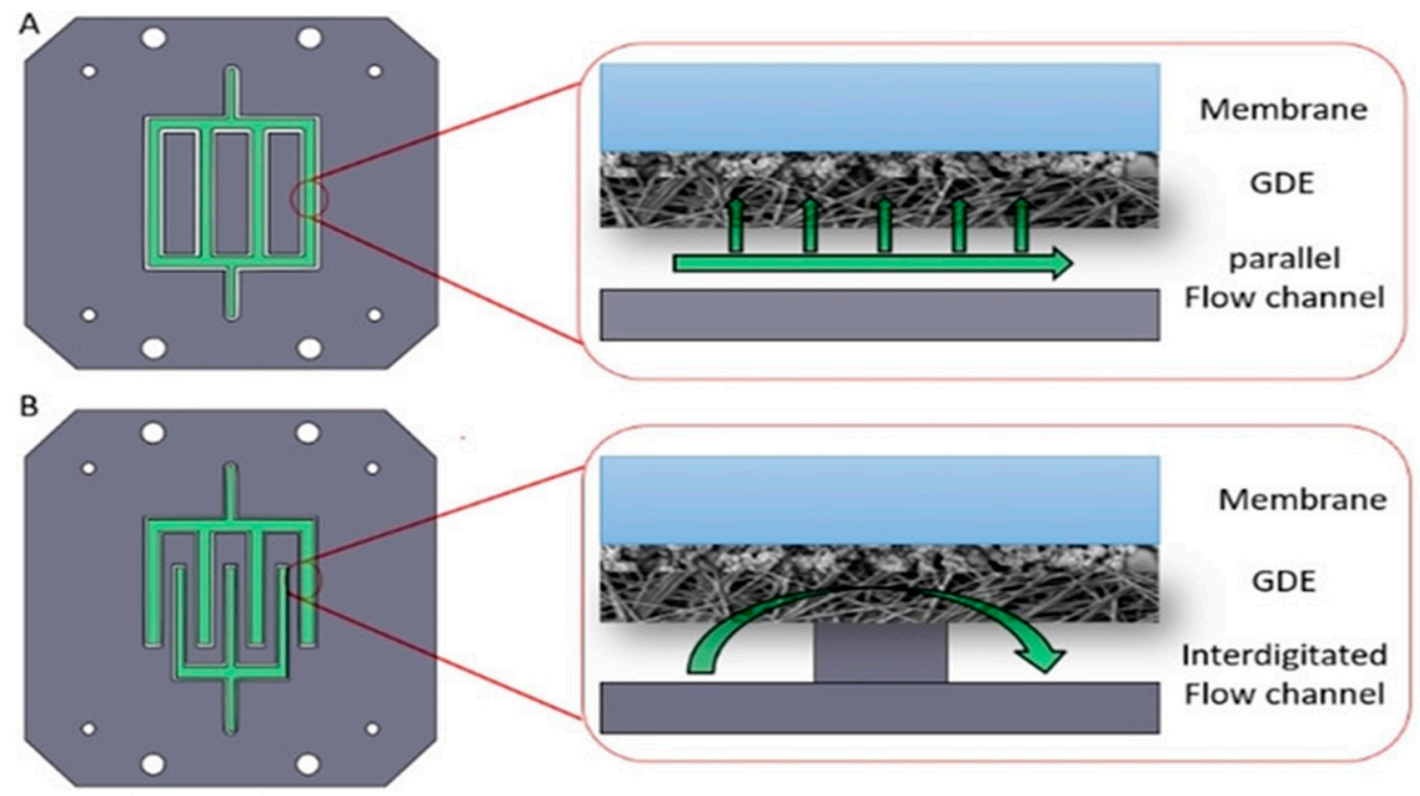

Figure 4. Schematic diagrams of the flow field patterns in the two types of zero-gap electrolyzer: (A) the parallel pattern, in, which mass transfer is due to diffusion, and (B) the interdigitated pattern, in, which mass transfer is a combination of diffusion and convection. Reproduced with permission from ref. [43]. Copyright 2020, Wiley-VCH.

In a similar study by W. H. Lee et al., a nanostructured Ag-based GDE was incorporated into an AEM zero-gap electrolyzer for converting $\mathrm{CO}_{2}$ to $\mathrm{CO}$ [40]. The silver catalyst layers were deposited onto polytetrafluoroethylene (PTFE)-coated carbon paper using an e-beam irradiation technique to produce an electrode designated as e- $\mathrm{Ag}$. In addition, humidified $\mathrm{CO}_{2}$ was used as the cathode reactant instead of a $\mathrm{CO}_{2}$-saturated electrolyte in order to increase the upper limit of $\mathrm{CO}_{2}$ mass transfer. For comparison, additional experiments were conducted using an electrochemical $\mathrm{H}$-cell in $\mathrm{CO}_{2}$-saturated $0.5 \mathrm{M} \mathrm{KHCO}_{3}$ and a zero-gap $\mathrm{CO}_{2} \mathrm{GDE}$ flow electrolyzer. The results demonstrated that the zero-gap $\mathrm{CO}_{2}$ $\mathrm{GDE}$ has a higher current density, lower overpotential, and higher $\mathrm{FE}_{\mathrm{CO}}$ than the H-cell. The maximum $\mathrm{CO}$ partial current density of the e-Ag coral electrode in the zero-gap $\mathrm{CO}_{2}$ flow was $312 \mathrm{~mA} \mathrm{~cm}^{-2}$ at $-0.79 \mathrm{~V}$ vs. reversible hydrogen electrode (RHE) compared to only $2.7 \mathrm{~mA} \mathrm{~cm}^{-2}$ at $-1.08 \mathrm{~V}$ vs. RHE for the $\mathrm{H}$-type cell. In addition, the $\mathrm{FE}_{\mathrm{CO}}$ values of all the Ag-based electrodes were essentially $100 \%$ in the $2.5-3.5 \mathrm{~V}$ cell voltage region, thus indicating their favorable efficiencies in the zero-gap $\mathrm{CO}_{2}$ flow. These results also indicate that the zero-gap electrolyzer with a porous structure can achieve suitably high current densities and durability for large-scale application.

\subsubsection{The Multilayer Electrolyzer Stack}

By combining the zero-gap electrolyzer with a stacking methodology, a suitable current density of $200 \mathrm{~mA} \mathrm{~cm}^{-2}$ for commercialization can be obtained. Moreover, the modular nature of the technology enables the production of multi-cell stacks, thus leading to low-cost structural materials for interconnects, gas diffusion layers (GDLs), and catalyst layers [44]. This strategy is well-established in fuel cells and polymer electrolyte membrane (PEM) water electrolyzers but has not been commonly used in $\mathrm{CO}_{2}$ electroreduction. Nevertheless, a zero-gap $\mathrm{CO}_{2}$ electrolyzer stack consisting of multiple electrolyzer layers and capable 
of operation without the need for either pressurized $\mathrm{CO}_{2}$ gas or a liquid catholyte has been described by B. Endrodi et al. [42]. The advantages of two different connections with respect to the distribution of the reactant $\mathrm{CO}_{2}$ gas were described, namely: (i) parallel connection, in, which the electrochemically active surface area is increased without any increase in the lateral size of the electrolyzer, and (ii) series connection, in, which the remaining unconverted $\mathrm{CO}_{2}$ gas from the first layer is fed into the subsequent layers for transformation into products, thus enabling a very high conversion efficiency. Because multiple single-cell electrolyzers operating in parallel have been shown to provide very similar FE values to that of a 3-layer electrolyzer stack, the use of a multilayer can lead to a reduction in capital cost, thus potentially assisting with industrial implementation. This is because the electrolyzer frame and the anolyte circulation loop only need to be built once, and the additional cells only require an additional bipolar plate, insulation, and membrane electrode assembly. Moreover, the use of the series connection resulted in a significant increase of $\sim 70 \%$ in the $\mathrm{CO}_{2}$ conversion rate compared to that of the single-layer cell (i.e., $20 \%$ ), even at low $\mathrm{CO}_{2}$ feed rates. At a higher gas feed rate, the FE for $\mathrm{CO}$ production was $>95 \%$ in the electrolyzer stack [42].

\section{Conceptual Process Design and Techno-Economic Analysis for Mass Production}

\subsection{Product Separation}

Due to the incomplete conversion of the $\mathrm{CO}_{2}$ reactants by the electrolysis system, it is beneficial to separate the unreacted $\mathrm{CO}_{2}$ from other gaseous products and recycle it back to the upstream electrolytic process $[28,45]$. Thus, the overall conversion of $\mathrm{CO}_{2}$ can be increased. In addition, the use of solid electrolytes can reduce the need for product separation. Typically, the resulting liquid product is mixed with a solute in the electrolyte of the $\mathrm{H}$ - or flow-cell reactor and extra separation and concentration stages are required in order to recover the pure liquid in solution. However, solid ion conductors assist in the formation of pure products by transporting the electrically generated cations or anions, thus preventing them from mixing with the solute and shortening the separation process.

$\mathrm{A} \mathrm{CO}_{2} \mathrm{RR}$ system using a solid-state electrolyte (SSE) instead of the conventional dissolved solute to conduct ions such as the proton $\left(\mathrm{H}^{+}\right)$or formate $\left(\mathrm{HCOO}^{-}\right)$ion and obtain a liquid $\mathrm{HCOOH}$ product was described by Chuan Xia et al. [45]. To further improve the performance, a four-chamber solid electrocatalytic cell was used to produce $\mathrm{H}^{+}, \mathrm{OH}^{-}$, $\mathrm{KOH}$, and $\mathrm{HCOOH}$ at the same time. The results indicated that a peak $\mathrm{HCOOH}$ partial current of about $150 \mathrm{~mA} \mathrm{~cm}^{-2}$ could be achieved at $3.36 \mathrm{~V}$. More important, a pure $\mathrm{KOH}$ electrolyte solution with a concentration of up to $0.66 \mathrm{M}$ was successfully collected at a deionized (DI) water flow rate of $16.2 \mathrm{~mL} \mathrm{~h}^{-1}$, thus demonstrating the feasibility of future application [45]. However, the use of DI water limits the product concentration, and a liquid electrolyte is still needed for the oxidation reaction at the anode.

By contrast, more recent papers by Lei Fan et al. have introduced an all-solid-state reactor that overcomes the above limitations for producing formic acid from $\mathrm{CO}_{2}$, as shown in Figure 5 [29]. Here, a GDL was used for both the cathode and anode in order to improve the mass transfer of $\mathrm{CO}_{2}$ and $\mathrm{H}_{2}$, and a flow of inert gas $\left(\mathrm{N}_{2}\right)$ was used instead of DI water to carry away the formic acid vapors and, thus, provide a high-concentration product. The most remarkable aspect of the all-solid-state reactor was the ultra-high purity of the obtained formic acid solution, which contained less than $0.01 \mathrm{ppm}$ iron, bismuth, and platinum, along with low levels of other impurities, as revealed by inductively coupled plasma atomic emission spectroscopy (ICP-OES). This level of purity is economically promising, as there are few additional separation steps required downstream. 


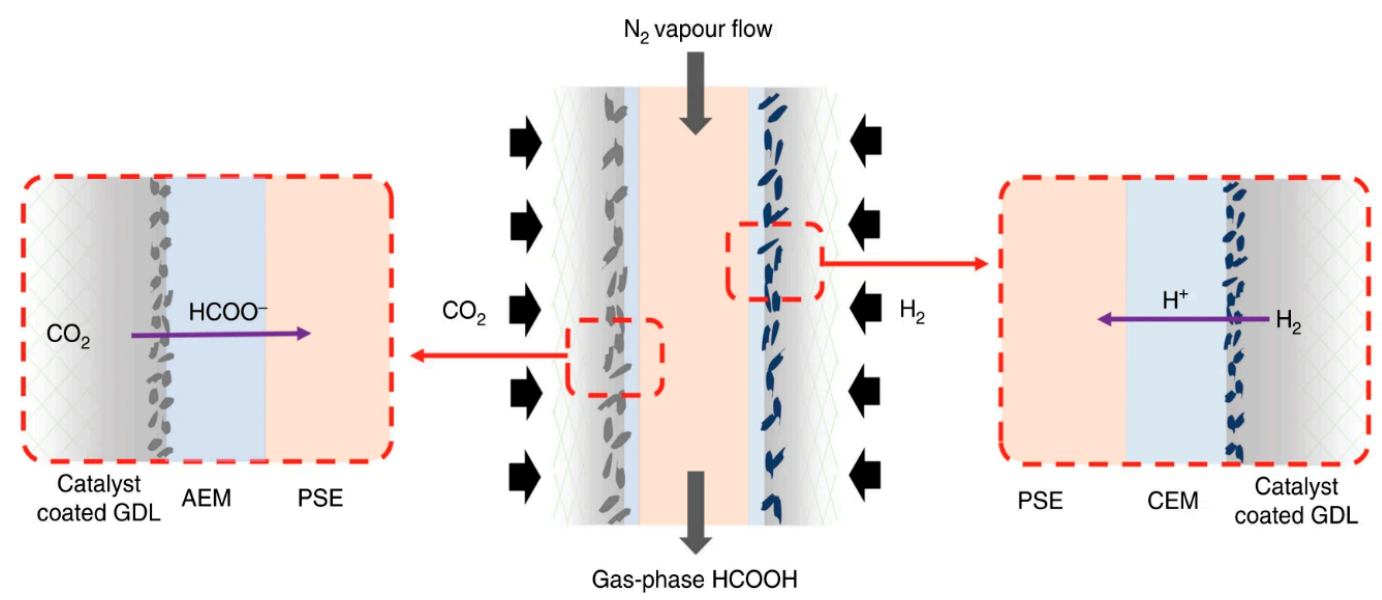

Figure 5. Schematic illustration of the all-solid-state electrochemical $\mathrm{CO}_{2}$ to formic acid reactor: $\mathrm{EM}=$ anion exchange membrane, $\mathrm{CEM}$ = cation exchange membrane, GDL = gas diffusion layer, $\mathrm{PSE}$ = porous solid electrolyte. Electrochemically generated $\mathrm{HCOO}^{-}$and $\mathrm{H}^{+}$ions are driven by the electric field to move across the EM or CEM into the PSE layer, where they recombine to form the formic acid molecule. This can then be released quickly in the vapor phase via the $\mathrm{N}_{2}$ carrier gas flow. Reproduced with permission from ref. [29] Copyright 2020, Springer Nature.

\subsection{Renewable Energy for Electricity}

One strategy for lowering the production cost would be the use of a renewable energy source. The change in the global weighted-average levelized cost of electricity (LCOE) for utility-scale renewable power generation technologies between 2010 and 2019 is indicated in Figure 6. In 2019, the LCOEs of most renewable power technologies were within the gray box representing the cost of fossil fuel power generation, thus indicating that the use of cheap, easily accessible renewable energy is an attractive approach to producing carbon chemical feedstocks in a carbon-neutral way via electrochemical $\mathrm{CO}_{2}$ reduction [10].

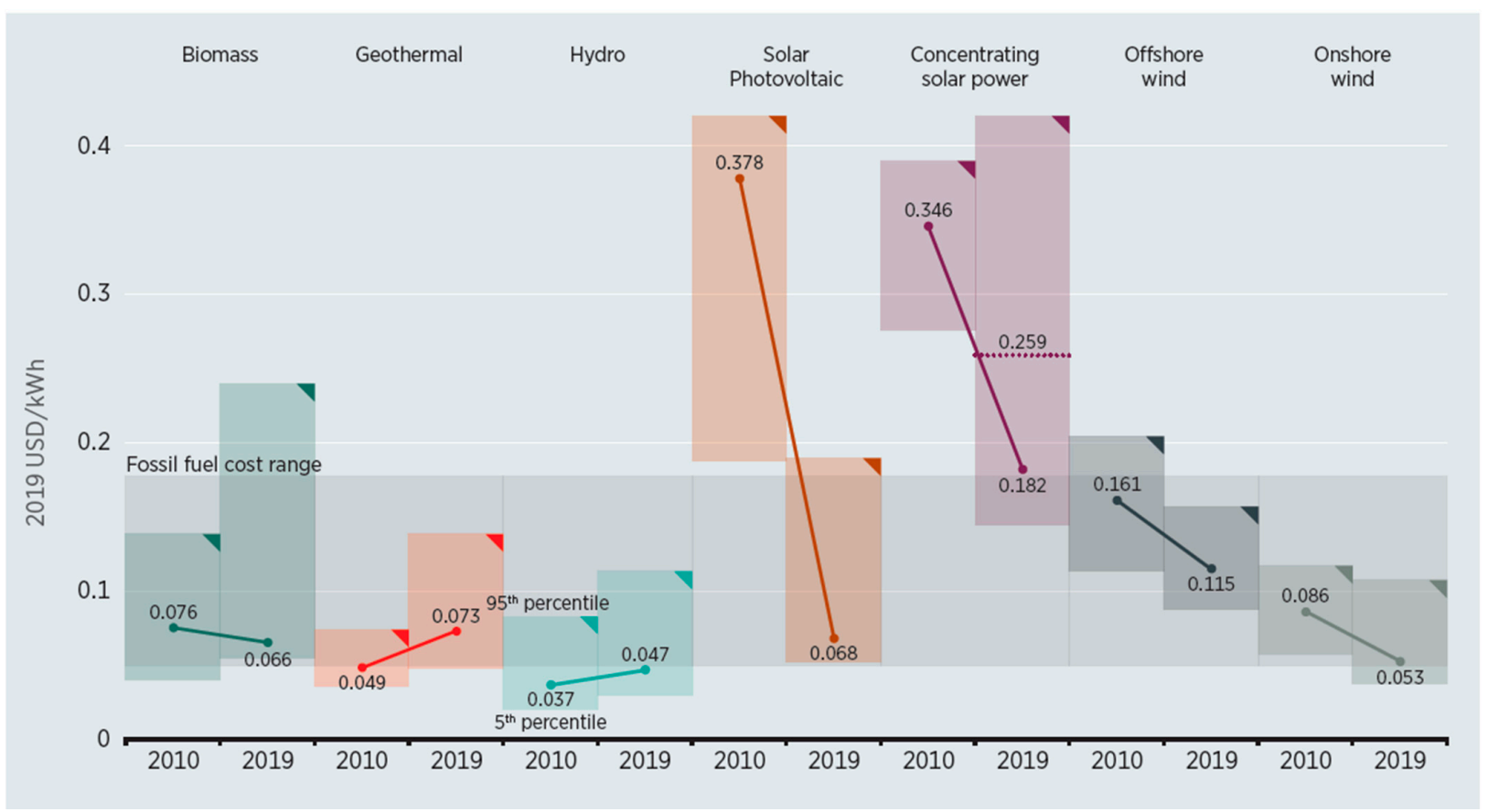

Figure 6. The global weighted average levelized cost of electricity (LCOE) from utility-scale renewable power generation technologies between 2010 and 2019. Reproduced with permission from ref. [46]. Copyright @ IRENA 2020. 
Renewable energy resources such as wind, solar, hydroelectric, and geothermal energies can be utilized for the electrochemical conversion of $\mathrm{CO}_{2}$ to useful chemicals [47]. Notably, the global weighted-average LCOE of utility-scale solar photovoltaics (PVs) fell by $82 \%$ (from 0.378 to $0.068 \$ / \mathrm{kWh}$ ) between 2010 and 2019 due to the decline in module prices. In addition to its low cost, solar energy is advantageous in that it can be used to provide both electrical and thermal energy [48]. A study on the use of solar energy as a source of electricity for $\mathrm{CO}_{2}$ reduction was performed by W. H. Cheng et al. using a gas diffusion electrode (GDE) directly powered by a photovoltaic cell [49]. Under simulated laboratory conditions with AM $1.5 \mathrm{G}$ (1 sun) illumination, a very high solar-to-CO efficiency of $19.1 \%$ was achieved during $20 \mathrm{~h}$ of operation. Moreover, the GDE remained stable and did not degrade even after more than $150 \mathrm{~h}$, thus indicating the good performance and stability of the solar-powered PV-EC process. Nevertheless, the following challenges to the use of renewable energy sources still remain: (i) its use is limited to certain locations according to availability; (ii) wind and solar energy are also intermittent and, hence, cannot be used to provide reliable energy. Hence, to address these problems, renewable energy sources must be modified in some way [48].

\subsection{Integrated Process Design}

To commercialize the electrochemical $\mathrm{CO}_{2}$-reduction system, studies on the optimization of large-scale systems are required. Although not many studies have been conducted, some pilot-level studies were recently reported by K. Kim et al. [13]. For instance, a continuous pilot-scale electroreduction system for converting $\mathrm{CO}_{2}$ into $\mathrm{CO}$ was constructed and operated, and the optimum operating conditions for maximum $\mathrm{CO}$ production were obtained via Gaussian process Bayesian optimization (GPBO) with the operating variables as input. A maximum $\mathrm{CO}$ partial current density of $51.14 \mathrm{~mA} \mathrm{~cm}^{-2}$ was achieved within 25 experiments. Although this experiment was conducted on a pilot scale, this type of optimization process may be applicable for mass production.

In addition, a study on the superstructure that examined every possible process design for $\mathrm{CO}_{2} \mathrm{RR}$-OOR coproduction, product separation, and recycling options has recently been described by J. Na et al. [7]. The superstructure is shown in Figure 7. The process design was automatically obtained using the Aspen Plus process simulator, which could not only design the full process, but also indicated the FE, current density, and overpotential, which are essential for large-scale operation. The results suggested that among $\mathrm{CO}_{2} \mathrm{RR}-\mathrm{OOR}$ combinations, the direct synthesis of ethanol, $n$-propanol, acetaldehyde, and (especially) ethylene without the need to synthesize their precursors is a promising approach in terms of electrochemistry. 


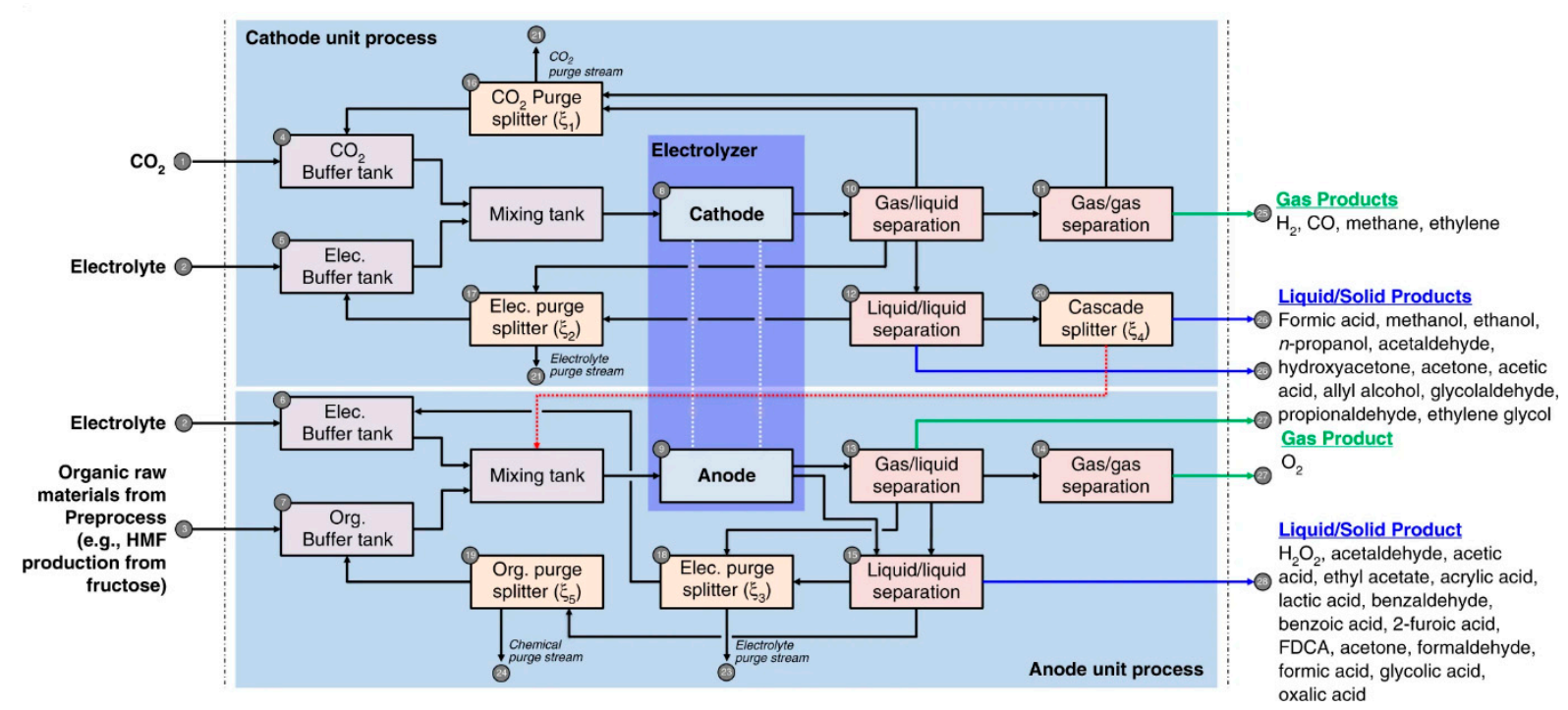

Figure 7. The superstructure of the electrochemical coproduction process is used to simultaneously consider all possible structures of the process. Reproduced with permission from ref. [7], copyright 2019, Springer Nature.

\section{Stability Issues}

For the commercialization of $\mathrm{CO}_{2} \mathrm{RR}$, high product selectivity and production rates, along with low electrical power usage, are favored. In the study of electrocatalytic $\mathrm{CO}_{2} \mathrm{RR}$, however, one prevalent issue that has often been overlooked is semipermanent stability. In addition, the long operation time must be addressed in order to achieve cost efficiency in mass production. As shown in Figure 8, we found that the levelized costs of chemicals (LCC) obtained from the electrochemical process, which represents the minimum selling cost for a net present value of 0 , become smaller than the market prices at least after $2000 \mathrm{~h}$ of operation in the optimum scenario ( $100 \%$ recycling of the electrolyte, no labor-related costs, and a subsidized solar PV electricity cost of $\$ 0.032 \mathrm{kWh}^{-1}$ ). The LCC of CO and $\mathrm{HCOOH}$ is highly sensitive to the catalyst life due to the increased maintenance costs associated with replacing the deactivated catalysts. A shorter life leads to an exponential increase in the maintenance cost and, hence, practical economic infeasibility. Therefore, from the economic point of view, it is very important to consider the previously reported stability issues. Specifically, catalyst poisoning, restructuring, compositional alteration, and flooding behavior are addressed in the following sections. 


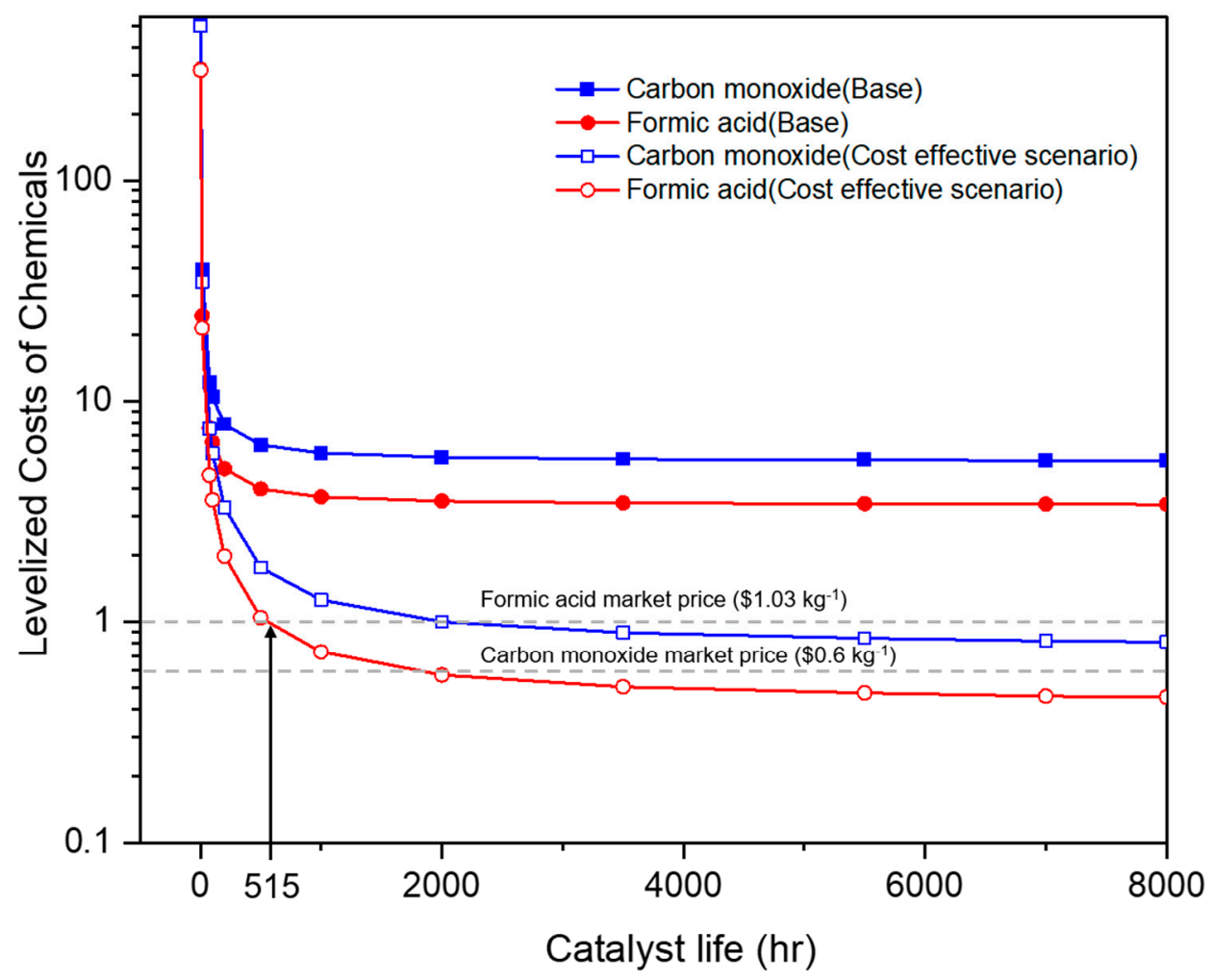

Figure 8. A techno-economic analysis of carbon monoxide and formic acid production via the electrochemical $\mathrm{CO}_{2}$-reduction process throughout the catalyst's operative life under different scenarios. The process models and parameters of analysis are based on Na et al. [7].

\subsection{Catalyst Poisoning}

Many studies have reported that the performance of the electrocatalytic $\mathrm{CO}_{2}$ reduction reaction $\left(\mathrm{CO}_{2} \mathrm{RR}\right)$ is compromised during electrolysis [2,50-52]. This is often attributed to catalyst deactivation by the adsorption of reaction intermediates. In the multiple steps of $\mathrm{CO}_{2}$ reduction, various intermediates formed and adsorbed at the catalyst surface are either subsequently released to the bulk electrolyte or undergo further reactions. Too strong an attachment of the adsorbed species, due to a high binding affinity to the catalyst surface, leads to the blocking of active sites, thus preventing fresh reactant from entering and taking part in the reduction reaction. In this section, the main catalyst deactivation mechanism during the $\mathrm{CO}_{2} \mathrm{RR}$ due to poisoning by reaction intermediates and other system impurities is discussed.

In a report by Rahman et al., the rapid decay in $\mathrm{CH}_{4}$ production in the presence of electropolished $\mathrm{Cu}$ was observed and was correlated with the absorption of a carbonaceous product by the catalyst surface, as revealed by the carbon signal measured by X-ray photoelectron spectroscopy (XPS) [2]. Similarly, Weng et al. reported the accumulation of carbonaceous species on the catalyst surface and illustrated the process schematically, as reproduced in Figure 9a [53]. During $2 \mathrm{~h}$ of electrolysis, this was shown to significantly decrease the FE from $56 \%$ to $13 \%$ for the formation of the hydrocarbons methane and ethylene and to increase the level of $\mathrm{H}_{2}$ evolution from $30 \%$ to $80 \%$. An analysis of the changes in the $\mathrm{C} / \mathrm{Cu}$ ratio of the C1s XPS spectra over the course of the electrolysis time also indicated that, while no metal species were deposited on the catalyst, the quantity of adsorbed carbonaceous species derived from $\mathrm{HCO}_{3}{ }^{-}$or $\mathrm{CO}_{2}$ was considerably increased (Figure $9 \mathrm{~b}$ ). Further deconvolution of the $\mathrm{C} 1 \mathrm{~s}$ spectra (Figure 9c) revealed the various types of bonds formed at the surface, thus indicating severe screening of the catalyst surface by carbon compounds [53]. 

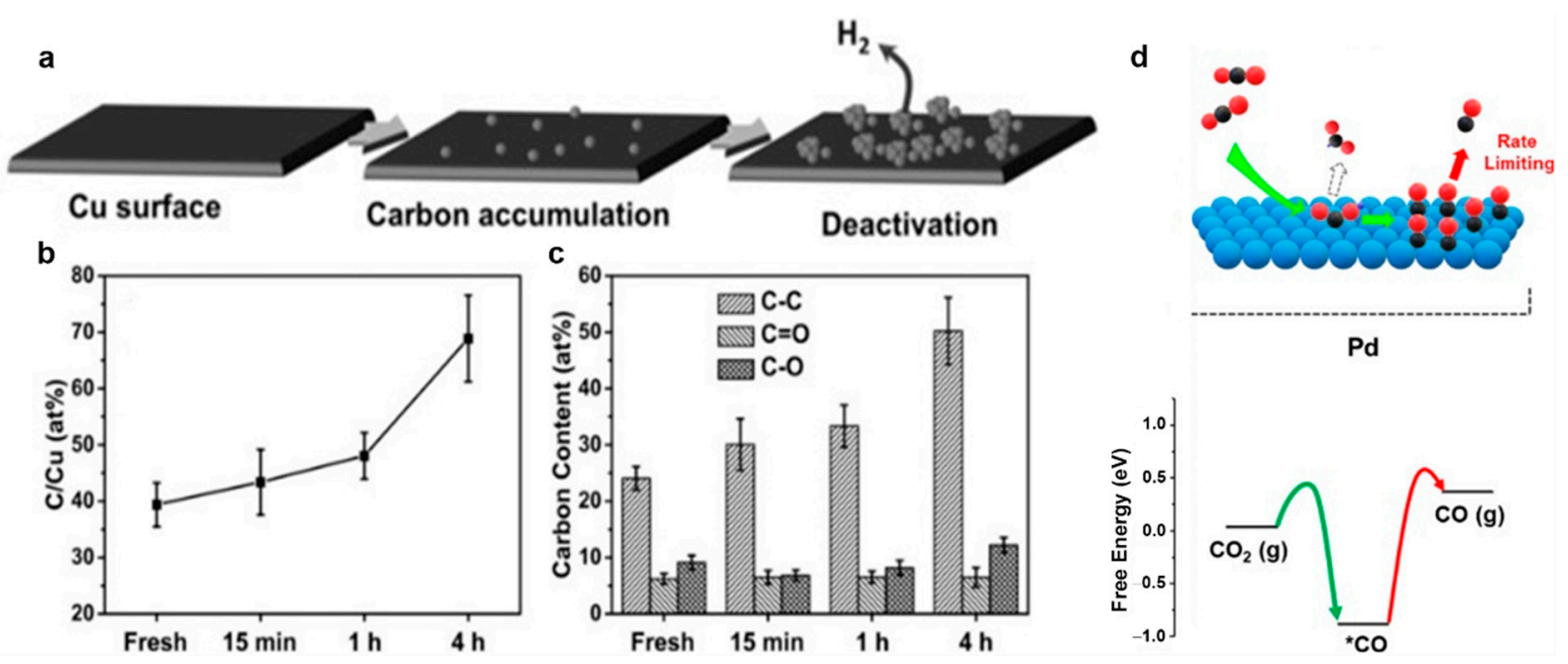

Figure 9. Catalyst deactivation mechanism by poisoning: (a) schematic diagrams showing carbon accumulation on a copper catalyst surface; $(\mathbf{b})$ the calculated $\mathrm{C} / \mathrm{Cu}$ ratios on the catalyst surface after electrochemical carbon dioxide reduction reaction $\left(\mathrm{CO}_{2} \mathrm{RR}\right)$ for various times; (c) bar chart indicating the types and relative abundances of carbonaceous bond observed on the catalyst surface after electrochemical $\mathrm{CO}_{2} \mathrm{RR}$ (reproduced with permission from ref. [53], copyright 2017, WILEY-VCH); (d) schematic illustration of the $\mathrm{CO}$ poisoning of a Pd electrocatalyst due to the strong binding (large desorption energy barrier) of CO (reproduced with permission from ref. [54], copyright 2019, ACS).

In addition, the applied potential has been suggested to intensify the poisoning behavior. For instance, a more recent report by Dutta et al. indicated a more severe degradation behavior of $\mathrm{Ag}$ foam when used for $\mathrm{CH}_{4}$ production at a more negative potential of $-1.14 \mathrm{~V}$ vs. RHE than that observed when used for $\mathrm{CO}$ production at the less negative potential of $-0.8 \mathrm{~V}$ vs. RHE [55]. It was suggested that this might have been due to high coverage of ${ }^{*} \mathrm{C}$ chemisorption at the catalyst surface, thus preventing $\mathrm{C}-\mathrm{H}$ bond formation in the $\mathrm{CH}_{4}$ pathway [56].

Many studies have shown a strong correlation between intermediate poisoning and the binding energy of the adsorbed species to the catalyst, such that the stronger the binding, the more adsorbed species tend to stay on the catalyst surface. Thus, density-functional theory (DFT) calculations have often revealed higher binding energy between the poisoned catalysts and the implicated species. For instance, Pd metal is known to bind strongly to $\mathrm{CO}$ and is more likely to be poisoned and undergo activity degradation in a short duration of time due to the reduction of $\mathrm{CO}_{2}$ to $\mathrm{CO}$ [50-52]. The strong $\mathrm{CO}$ adsorption arises from an increase in $2 \pi^{*}$ back donation interaction (i.e., electron donation from the $\mathrm{d}$ orbitals of the metal substrate to the $2 \pi^{*}$ orbital of $\mathrm{CO}$ ) as the formed bonding resonances are filled at a more negative potential [57]. This, in turn, leads to a high CO coverage, along with a high chemical desorption energy barrier (Figure 9d) [54,58], thus blocking the active sites [56]. The $\mathrm{CO}$ accumulation can also be observed by in situ measurement techniques, such as Raman spectroscopy [59]. This technique is found to be useful in understanding the intrinsic interaction behavior between the catalyst surface and the adsorbed reaction intermediate.

In addition to the above-mentioned issues, another type of poisoning phenomenon was observed in a study by Hori et al. [60], where a deterioration in catalyst activity was associated with the deposition of metal impurities from the electrolyte onto the catalyst surface to form a new layer that both blocks the original active sites and provides activity towards the hydrogen evolution reaction $[53,55,61]$. This finding was supported by later studies that indicated the deposition of metal impurities, which may be present even in trace amounts in the electrolyte, the water source, the electrocatalyst, or the support materials [62]. Some studies even found that metal contaminants can be present due to the dissolution of the oxygen-evolution catalyst at the anode used as the counter electrode for the $\mathrm{CO}_{2} \mathrm{RR}$ and its subsequent re-deposition at the cathode, where it interferes with the 
$\mathrm{CO}_{2} \mathrm{RR}$ activity $[63,64]$. As stated by Won et al., the deposition of metal impurities is also problematic in the electrocatalytic $\mathrm{CO}_{2} \mathrm{RR}$ due to the complex steps and the susceptibility of the metal to deposition in the reductive potential environment $[64,65]$.

\subsection{Catalyst Restructuring}

Mostly, enhancing the catalyst activity in electrochemical $\mathrm{CO}_{2}$ reduction involves tailoring the crystal morphology to better expose the active catalytic sites $[66,67]$. This strategy is known to provide energetically preferred sites for the adsorption of the desired $\mathrm{CO}_{2}$ reduction intermediate. However, in a reductive environment during electrocatalytic $\mathrm{CO}_{2}$ reduction, nanosized particles seldom succeed in retaining their structure due to the high-energy of the surface compared to the bulk material $[64,68]$. Although some studies have mentioned the importance of surface reconstructing for providing a fresh available catalyst surface and enhancing its electrochemical characteristics [69], more studies have attributed the observed degradation of catalyst activity and selectivity to transformations of the existing surface that alter the structure of the active sites. Hence, the following paragraphs examine the relationship between catalyst deactivation and restructuring.

The catalyst surface morphology has been acknowledged as one of the most important factors determining the catalyst activity and selectivity, especially in a heterogeneous electrocatalytic system [70]. The control of morphological features such as facets, grain boundaries, edges, corners, and surface distortions cannot only control the electronic structure of the catalyst but also influence the surface wettability, the adsorption/desorption behavior of various species, mass transportation, and external conditions such as the local $\mathrm{CO}_{2}$ concentration and $\mathrm{pH}$ value. Superior electrocatalysts have been shown to possess high densities of low-coordinated atoms as highly active sites, along with rougher surfaces and, hence, higher electrochemical active surface area (ECSA) values. The latter index affects the total reaction rate by allowing more reactants to reach the active catalyst sites [71]. For example, the direct growth of tin with an ordered cone-like structure on carbon paper was shown to produce a catalyst that effectively reduced $\mathrm{CO}_{2}$ to formate at a low onset potential of $-0.46 \mathrm{~V}$ vs. RHE (which is $110 \mathrm{mV}$ more positive than that of Sn-N-60) and a high FE of $92 \%$ at $-1.13 \mathrm{~V}$ [70]. The improved activity was attributed to the improved morphology of the catalyst, which provided a higher ratio of active stepped sites on the higher preferential facets [70]. However, as the reaction progressed, these well-designed catalysts were unable to retain their morphologies and underwent restructuring, thus leading to a deterioration in activity $[55,72,73]$.

The catalyst restructuring mechanism is shown schematically in Figure 10a-c [74], and is easily detected via microscopic examination, as shown in Figure 10b,c [74]. Here, the coalescence of an Ag-foam catalyst is clearly seen in the scanning electron microscope (SEM) images of the same location before and after $\mathrm{CO}_{2}$ electroreduction. In addition, in the case of a dispersed catalyst on a support material, where the particle size can be measured independently, the change in particle size and particle size distribution due to sintering during electrocatalysis can also be quantified via transmission electron microscopy (TEM). For instance, Duan et al. used this approach to reveal an increase in the average size of crystalline $\mathrm{Cu}$ nanoparticles (NPs) due to degradation during use in the $\mathrm{CO}_{2}$ reduction reaction [75]. This is attributed to the tendency for the small nanosized particles to adjust their surface energy via various widely-known particle growth mechanisms such as Ostwald ripening, coalescence, and reprecipitation [76,77]. In detail, Huang et al. observed a continuous decrease in the production of $\mathrm{C}_{2} \mathrm{H}_{4}$ by the electroreduction of $\mathrm{CO}_{2}$, and a continuous increase in hydrogen evolution, in the presence of $\mathrm{Cu}$ nanocubes (CuNC) as the catalyst (Figure 10a) [74]. In addition, the application of a highly negative potential to the $\mathrm{CO}$-adsorbing catalyst was shown to promote an increase in catalyst mobility with decreasing particle size (with $\sim 16 \mathrm{~nm}$-sized particles exhibiting the fastest growth), thus leading to the formation of nanoclusters, which subsequently coalesced to form aggregates with few remaining active facets. Moreover, DFT calculations revealed a correlation between the tendency towards restructuring (loss of the cubic form) and a 
decrease in the interface energies for the (111) and (110) $\mathrm{Cu}$ surfaces when adsorbates were attached.

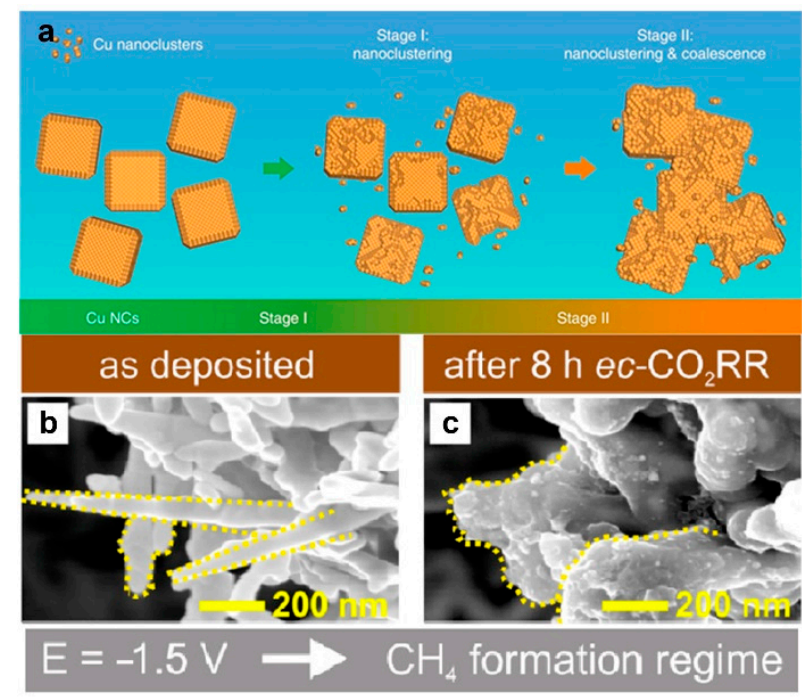

Figure 10. Catalyst restructuring: (a) schematic restructuring mechanism of the $\mathrm{CuNC}$ catalyst during the $\mathrm{CO}_{2} \mathrm{RR}$, including nanoclustering (stage I) followed by coalescence (stage II) (reproduced with permission from ref. [74], copyright 2018, Springer Nature); (b,c) SEM images of the same location on an Ag-foam catalyst (b) before, and (c) after the electrochemical $\mathrm{CO}_{2} \mathrm{RR}$ at $-1.5 \mathrm{~V}$ vs. RHE, showing restructuring of the catalyst (reproduced with permission from ref. [55], copyright 2018, ACS).

Hence, a careful investigation of catalyst morphology before and after the $\mathrm{CO}_{2} \mathrm{RR}$ is essential for a better understanding of the relationship between the morphology and activity of the catalyst [76,78]. In particular, as the catalyst particle size changes during the reaction, the actual effective size of the catalyst should be investigated closely [76]. For instance, while an Au particle with a size of $\sim 2 \mathrm{~nm}$ has been reported as a robust and efficient catalyst for $\mathrm{CO}_{2}$ electroreduction $[79,80]$, a recent study by Trindell et al. found that a catalyst consisting of 2-nm sized Au particles encapsulated in a hydroxyl-terminated poly(amidoamine) dendrimer exhibits a higher activity towards the production of $\mathrm{H}_{2}$ rather than $\mathrm{CO}$, in agreement with a previous study on the hydrogen evolution reaction (HER) [81]. In addition to pre- and post-reaction characterization, in situ measurement have also been found useful in giving the real-time dynamic change of the catalyst surface morphology during $\mathrm{CO}_{2}$ electroreduction. Great achievements in acquiring morphological information of the catalyst surface have been the use of in situ XRD, EXAFS, and environment transmission electron microscopy (ETEM) [82]. For example, a study by Damsgaard et al. utilizes in situ ETEM to follow the morphological evolution of the catalyst surface, $\mathrm{GaPd}_{2}$. Complemented with in situ XRD and EXAFS results, it is useful to visualize the catalyst surface change during $\mathrm{CO}_{2}$ electroreduction [83]. Any degradation observed in the catalyst electrochemical activity, can be directly correlated with the information on morphological change during electrolysis operation.

\subsection{Changes in Catalyst Composition and Valency}

The presence of a metastable oxide layer on the catalyst surface often promotes $\mathrm{CO}_{2}$ reduction by stabilizing the intermediate [4]. However, in an electrocatalytic $\mathrm{CO}_{2}$-reduction system where the catalyst is being exposed to a certain potential, it is difficult to identify its chemical state. The change in the catalyst composition will also alter the catalyst activity [84]. For instance, the $\mathrm{Cu}(\mathrm{I})$ species with (100) facets is known for its selectivity towards $\mathrm{C}-\mathrm{C}$ coupling reactions and has therefore been proposed for $\mathrm{C}_{2}$ production, as indicated in Figure 11a $[85,86]$. In particular, a study by Lin et al. demonstrated that $\mathrm{Cu}-\mathrm{Cu}(\mathrm{I})$ ensembles could asymmetrically couple with two $\mathrm{CO}$ molecules, thus potentially enhancing the selectivity of the catalyst towards $C_{2}$ production [6]. To rule out the morphologic effect 
of the catalyst and carefully observe the effect of changing the surface oxidation state of the catalyst, oxide-derived copper was prepared using hexadecyl amine. Compared to the stable $\mathrm{Cu}(\mathrm{I}) / \mathrm{Cu}$ ratio when using a potential switching approach (Figure 11b), the $\mathrm{Cu}(\mathrm{I})$ exhibited a continuous reduction in its valency under steady application of a negative potential ( $-0.75 \mathrm{~V}$ vs. RHE) during chronoamperometry (Figure 11c). Further, although there is a negligible decrease in the current density, the reduction of $\mathrm{Cu}(\mathrm{I})$ to metallic $\mathrm{Cu}$ has been shown to shift the selectivity from the $C_{2+}$ pathway to the $C_{1}$ pathway $[2,72]$.
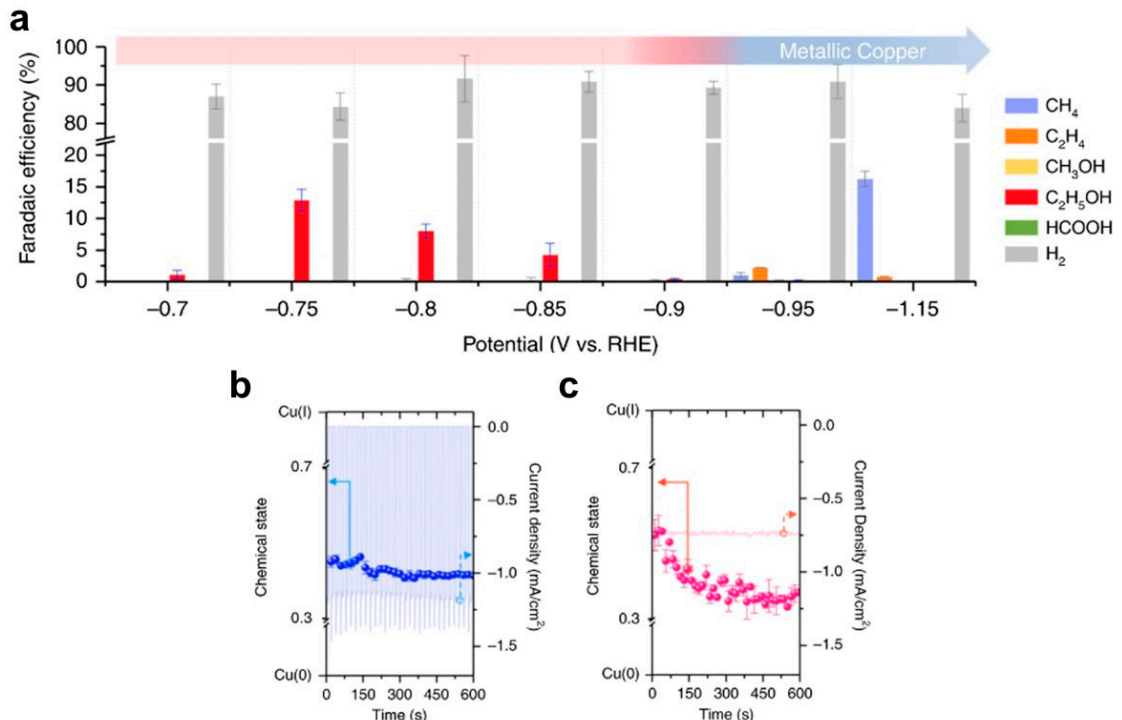

Figure 11. The effects of using a redox shuttle (i.e., an electrolyte additive capable of reversible oxidative-reductive reaction at a specific potential): (a) the potential dependence of the $\mathrm{CO}_{2} \mathrm{RR}$ product selectivity of the $\mathrm{CuO}_{x}$ catalyst in $0.5 \mathrm{M} \mathrm{CO}_{2}$-saturated $\mathrm{KHCO}_{3}$ when using a redox shuttle. The error bars represent the standard deviation based on three individual measurements; (b) the time-resolved variations in the $\mathrm{Cu}$ species in $\mathrm{CuO}_{\mathrm{x}}$ and the corresponding electrochemical responses during the $\mathrm{CO}_{2} \mathrm{RR}$ at $-0.75 \mathrm{~V}$ when using a redox shuttle; (c) for comparison, the time-resolved variations in the $\mathrm{Cu}$ species in $\mathrm{CuO}_{x}$ and the corresponding electrochemical responses during the $\mathrm{CO}_{2} \mathrm{RR}$ at $-0.75 \mathrm{~V}$, obtained using chronoamperometry (reproduced with permission from ref. [6], copyright 2020, Springer Nature).

Although the surface composition is key to modifying the reactant and/or intermediate bonding strength of alloy catalysts $[50,54,87]$, several cases have been reported in which the alloying materials undergo segregation during $\mathrm{CO}_{2}$ electroreduction $[88,89]$. For example, $\mathrm{Cu}$ surface enrichment was shown to occur in Ag-rich $\mathrm{CuAg}$ bimetallic electrodes during the first 20 min of electrolysis as measured using XPS and ion scattering spectroscopy (ISS) [90]. During this time, the initially dissolved $\mathrm{Cu}$ in the Ag phase segregated to the surface to form a Cu-rich skin with a thickness $\geq 1 \mathrm{~nm}$. This segregation was attributed to the stronger interaction of $\mathrm{CO}$ with $\mathrm{Cu}$ rather than $\mathrm{Ag}[90,91]$. As a result, the production of $\mathrm{CO}$ (which is favored on an Ag surface) was decreased, and that of ethylene (which is favored by a Cu surface) was increased.

\subsection{Electrolyte Flooding}

Given that the source feed gas must reach the catalyst surface in order to undergo reaction, one of the main limiting parameters for enhancing the rate of the $\mathrm{CO}_{2} \mathrm{RR}$ is mass transport. Hence, although conventional reactors (e.g., H-type cells) have been previously explored, these cannot be practically implemented due to the low solubility of $\mathrm{CO}_{2}$ in the aqueous electrolyte and slow mass transport to the catalyst surface, which results in a low current density. A continuous flow cell equipped with a GDL electrode has been proposed to address these drawbacks because it can provide an exceptional re-refreshed three-phase 
boundary between the electrolyte, catalyst, and $\mathrm{CO}_{2}$, thus enabling fast $\mathrm{CO}_{2}$ transfer [17]. The GDL electrode consists of micro- and macroporous layers and a catalyst layer, where the microporous layer serves as both a support for the catalyst layer and a barrier to keep the nearby electrolyte in its channel, while the macroporous layer serves as a gas diffusion medium and current collector [12]. It is worth noting that the three-phase boundary should be maintained, especially to prevent the electrolyte from entering the gas channel, since the presence of a liquid may limit the effective concentration of the gas near the catalyst. As the micro- and macropores play important roles in this respect, they should possess a good balance between hydrophilicity and hydrophobicity. However, the increase in the hydrophilicity of the electrode as the reaction proceeds causes the electrolyte to become immersed in the catalyst layer, thus preventing the gas from contacting the catalyst and taking part in the reduction reaction [92]. This phenomenon is widely known as electrode flooding and is shown schematically in Figure 12a. This issue leads to the formation of $\mathrm{H}_{2}$, the deterioration of $\mathrm{CO}_{2}$-reduction activity, and the blocking of available gas channels by precipitation of electrolyte salt underneath the electrode.

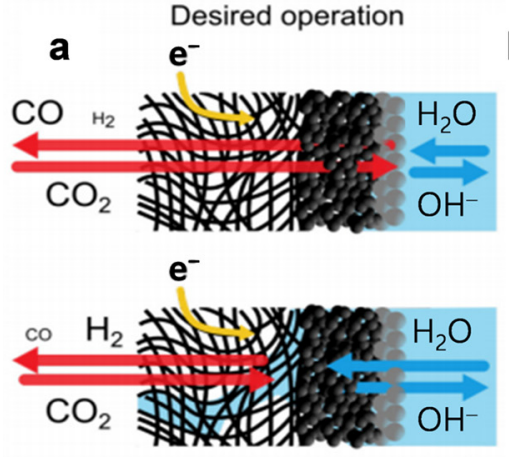

Flooded operation b

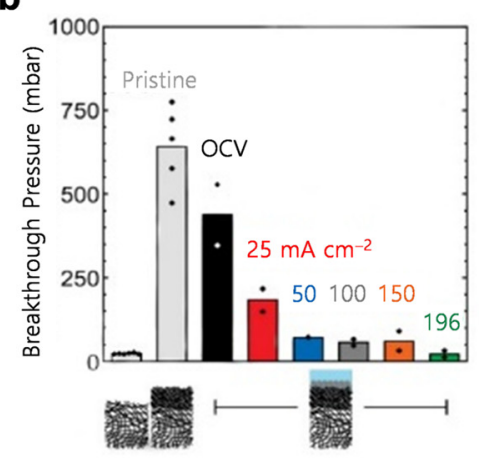

C

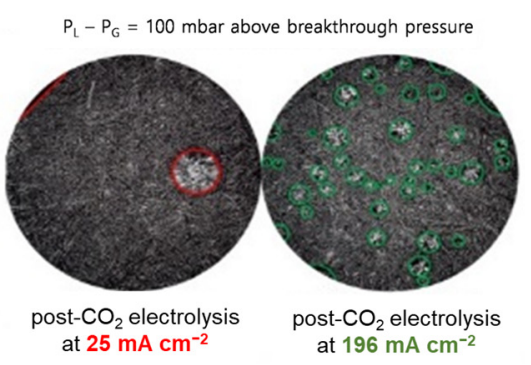

Figure 12. Degradation of the gas diffusion layers (GDL): (a) a schematic diagram showing the process of electrode flooding during electrochemical $\mathrm{CO}_{2}$ reduction; (b) the effects of current density upon GDL degradation; (c) a visualization of GDL degradation at different applied current densities (reproduced with permission from ref. [93], copyright 2020, WILEY VCH).

An understanding of the underlying mechanism of GDL degradation is important for formulating the correct strategy for the prevention of electrode flooding. For instance, when Dinh et al. observed degradation in activity within $1 \mathrm{~h}$ of $\mathrm{CO}_{2}$ electroreduction regardless of the catalyst or the electrolyte type, further investigations in which the reaction was performed on the GDL under a negative potential without catalyst deposition revealed a doubling of the oxygen content and a decrease in the hydrophobicity (water contact angle) of the GDL [94]. These effects were attributed to the presence of surface $\mathrm{OH}$ and $\mathrm{COOH}$ on the carbon electrode and led to obstruction of the $\mathrm{CO}_{2}$ diffusion pathway.

In addition to a change in the electrode wettability due to product formation, changes in the solid-electrolyte contact angle due to the applied potential difference between the solid and the electrolyte (the electro-wetting effect) $[95,96]$, and due to the production of ions and gas, may also affect the integrity of the GDE [97]. For example, Jeanty et al. observed the formation of droplets on the gas side of the porous layer (referred to as perspiration), which impeded $\mathrm{CO}_{2}$ permeation and produced an increasing quantity of salt precipitates under high gas pressure [97]. Similarly, Leonard et al. studied the effect of applied current density upon the electrode flooding behavior to demonstrate that high cathode alkalinity leads to a lower breakthrough pressure and a higher rate of electrolyte infiltration due to an increasing rate of carbonate salt precipitation (Figure 12b,c) [97].

Alongside the previously-mentioned flooding mechanisms, mechanical leaching of the catalyst from the GDL support may also cause a deterioration in activity. This behavior is also indicated by an increase in $\mathrm{H}_{2}$ production due to easier access of water to the catalytic sites [98]. Although the mechanism and cause of this material leaching have 
yet to be discovered, a valuable study by Bienen et al. may be useful in elucidating the underlying physical processes during the electroreduction of $\mathrm{CO}_{2}$ using a GDE; it was suggested that an EIS study might reveal the degradation mechanism and, thus, enable further optimization of the GDE for the $\mathrm{CO}_{2}$-reduction process [99].

\section{Existing Strategies in Overcoming Performance Stability Issues}

For a decade, many researchers have attempted to solve the stability issues and overcome the observed degradation of catalyst and electrode. Several such strategies that can help to provide a better understanding of the issues and to progress the development of the technology are discussed in the present section.

\subsection{Modifying the Electronic Structure}

In terms of catalyst design, modulating the electronic structure provides the benefits of directly adjusting the binding energies of the reaction intermediates. Thus, Zhang et al. [100] described several strategies for modifying the electronic structure, including the use of alloying [87,101], single-atom catalysts [102], phase-junction catalysts [61], and surface groups [69]. Among these strategies, the alloying of several metals are particularly promising for relieving the poisoning of the catalyst by intermediates. For example, the deactivation rate of Pd-based catalysts, which are known to be susceptible to CO poisoning, has been shown to be minimized when certain metals are introduced into the $\mathrm{Pd}$ lattice $[8-10,61]$. Thus, the strong CO-binding characteristics of Pd are lowered by incorporating a metal that has a weak affinity towards CO (usually a poor HER catalyst) [101]. In this respect, the $\mathrm{CO}$ and $\mathrm{H}$ binding energies of several $\mathrm{Pd}$ alloys have been calculated by Chatterjee et al. (Figure 13a) to find that the CO-binding energy decreases when the coadsorbed species $(\mathrm{H})$ is present on the catalyst surface [50]. This reduction in CO-binding energy also has been shown to be closely related to the specific type of alloying compound, with $\mathrm{Pd}_{3} \mathrm{Co}$ being both theoretically and experimentally the most resistant alloy against CO poisoning [55,74].
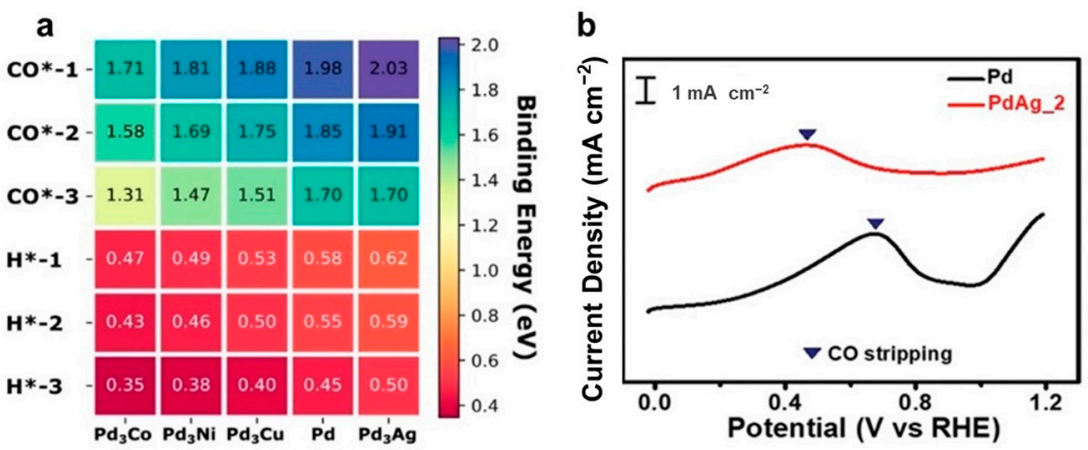

Figure 13. The influence of alloying and the presence of a co-adsorbent upon catalyst deactivation by $\mathrm{CO}$ : (a) the tabulated binding energies (in $\mathrm{eV}$ ) of $\mathrm{CO}$ to a clean surface $\left(\mathrm{CO}^{*}-1\right)$, a surface with coadsorbed $\mathrm{H}^{*}\left(\mathrm{CO}^{*}-2\right)$, and a surface with $2 \mathrm{H}^{*}\left(\mathrm{CO}^{*}-3\right)$, along with the binding of $\mathrm{H}$ to a clean surface $\left(\mathrm{H}^{*}-1\right)$, a surface with $\mathrm{H}^{*}\left(\mathrm{H}^{*}-2\right)$, and a surface with $\mathrm{CO}^{*}\left(\mathrm{H}^{*}-3\right)$ (reproduced with permission from ref. [50], copyright 2019, ACS); (b) linear sweep voltammetry of Pd and PdAg_2 immediately after application of a $-0.27 \mathrm{~V}$ bias for $1 \mathrm{~h}$ in $\mathrm{CO}_{2}$-saturated $0.1 \mathrm{M} \mathrm{KHCO}_{3}$ (reproduced with permission from ref. [51], copyright 2020, Wiley-VCH).

It has been commonly recognized that metal alloying can induce a lowering in the d-band center, possibly via charge transfer, thus allowing more electrons to fill the metaladsorbate antibonding orbitals, leading to a reduction in $\mathrm{CO}$ back bonding and, hence, a significant reduction in CO poisoning [51]. This is supported by linear sweep voltammetry (LSV) data indicating that the alloying of Pd with $\mathrm{Ag}$ results in a lower CO stripping peak due to a weaker $\mathrm{Pd}-\mathrm{CO}$ bond and, hence, a lower energy requirement for the removal 
of $\mathrm{CO}$ from the catalyst surface (Figure 13b) [51]. However, while positive results have been obtained by alloying $\mathrm{Pd}$ with $\mathrm{Au}$ [103] and Sn [63], the CO poisoning resistance of the partially covalent Pd-In alloy comes at the expense of the $\mathrm{CO}_{2}$-reduction activity [52]. Additionally, intermetallic compound studies may be important in resolving poisoning behaviors by tuning the geometric and electronic effects to obtain a catalyst with the desired adsorption behavior $[87,101]$.

The obvious importance of the above-mentioned alloying strategy makes it attractive for further implementation and development. Moreover, the electrochemical behavior of the alloy can be predicted via a DFT analysis of the reaction energetics [104,105]. For example, a study by Zheng et al. demonstrated that a theoretically calculated $\mathrm{Cu}-\mathrm{Sn}$ alloy could successfully produce formate with up to $95 \% \mathrm{FE}$ without any significant decrease for $50 \mathrm{~h}$ of operation [105]. In addition to minimizing catalyst poisoning by tuning the binding energy, this strategy could exert control towards the desired concentration of active species on the catalyst surface. For example, the change in morphology induced by alloying an $\mathrm{Sn}$ catalyst with $\mathrm{Sb}$ was shown to provide a balanced number of active species ( $\mathrm{Sn}$ atoms) on the catalyst surface [61].

Although the alloying strategy shows some promise for alleviating performance stability problems, its widespread practical application remains limited by the linear scaling relation between the adsorption energies of intermediates [71], as well as by the dynamic compositional changes taking place during the reaction $[106,107]$. Therefore, further enhancements and deeper investigations are needed in order to provide a better strategy for minimizing the performance degradation without sacrificing the activity itself.

\subsection{Utilization of Support Materials}

In addition to tuning the electronic structure of the catalyst material, the use of a support material has been shown to be practical for enhancing not only the electrochemical characteristics of the catalyst $[108,109]$ but also the retention of catalyst particles [110]. Further benefits of this strategy include preserving the original form of the material and providing a synergetic effect between $\mathrm{CO}_{2}$ adsorption and activation. Catalyst support materials are classified into two types, namely: carbon-based supports and metal compound supports. Further, as the material itself may possess an intrinsic activity towards $\mathrm{CO}_{2}$ electroreduction or other reactions, activity testing of the premodified supporting materials is usually performed.

According to studies on metal-free carbon material as $\mathrm{CO}_{2}$ electrocatalysts, the carbon materials themselves exhibited prolonged stable $\mathrm{CO}_{2}$ reduction activity [111,112]. In all the pre-existing studies, no major degradation was observed in the resulting electrolysis activity descriptors (current density and FE) and the resulting material characteristic after the reaction, which is inferred from before-after material characterization (SEM, TEM, or XPS). The stability is attributed to its high resistance or insensitivity to $\mathrm{CO}$, which normally causes performance attenuation in metal-based catalysts [111]. Additionally, the $\mathrm{CO}_{2}$ reduction activity in carbon-based materials is related to the characteristic electronic structure in the carbon vicinity, which may arise from its intrinsic structural defect or can be induced by heteroatom doping [112]. Unlike metal-based material whose activity greatly depends on the polycrystalline facets of the crystal [113], the carbon materials are less susceptible to activity degradation caused by morphological change due to their robust structure. However, the metal-free carbon materials are reported to have inferior activity compared to that of metal-based, namely the resulting current density and overpotential needed. Therefore, the additional metal decoration is encouraged to enhance the overall activity of the carbon material. When incorporating a metal catalyst into a carbon-based material, it is essential to ensure the corrosion resistance of the support, since corrosion could result in a decrease in the available metal surface area followed by metal sintering and leaching from the support [114].

The interaction between metal nanoparticles and the carbon support arises by charge transfer from the metal to the carbon support. Thus, according to a model by Hegenberger 
et al., an increase in the number of surface carbon atoms with uncompensated bonds will lead to an increase in the charge transfer between metal and support along with an increase in the stability of the metal particles towards sintering $[115,116]$. The carbon atoms with uncompensated bonds are usually present in the form of chemical or structural defects and can act as anchoring sites [117]. For example, although $\mathrm{Cu}$ nanoparticles (NPs) are prone to surface restructuring [73], the use of graphene oxide as a support has been shown to provide a stable ethanol production performance (FE 56.3\% at $-0.250 \mathrm{~V}$ vs. RHE) for

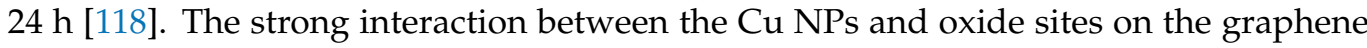
oxide creates a sufficient anchoring effect, thus stabilizing the size and morphology of the $\mathrm{Cu}$ NPs [116]. In another example, interconnected $\mathrm{SnO}_{2}$ nanocrystals were embedded in an $\mathrm{N}$-doped carbonaceous dopamine-based polymer, followed by carbonization under mild conditions to generate $\mathrm{SnO}_{2}-\mathrm{NCs}$ with great structural confinement of $\mathrm{SnO}_{2}$ nanocrystals $(\sim 8 \mathrm{~nm})$ and high-performance stability towards formate production at $-0.92 \mathrm{~V}$ with $\sim 73 \%$ FE for $20 \mathrm{~h} \mathrm{[73].} \mathrm{However,} \mathrm{it} \mathrm{also} \mathrm{has} \mathrm{been} \mathrm{noted} \mathrm{that} \mathrm{the} \mathrm{morphology} \mathrm{of} \mathrm{metal} \mathrm{nanoparticles}$ varies according to the initial size, so that size control is also important in determining the activity and stability of the catalyst [74].

The use of a metal compound support increases the electron density on the deposited metal due to a change in the lattice energy along with partial charge transfer from the substrate to the supported metals. The resulting chemical bonds help prevent the deposited metal from undergoing agglomeration $[119,120]$. For example, $\mathrm{Cu}_{3} \mathrm{~N}$ and $\mathrm{Cu}_{2} \mathrm{O}$ have been used as supports that stabilize the $\mathrm{Cu}(\mathrm{I})$ species, which is the active site for $\mathrm{C}_{2+}$ production (Figure 14a,b) [119]. Compared to the bulk $\mathrm{Cu}$ foil, the $\mathrm{Cu}$ supported on $\mathrm{Cu}_{2} \mathrm{O}$ and $\mathrm{Cu}_{3} \mathrm{~N}$ exhibited better stability with respect to time, as demonstrated in Figure 14c. A difference in the relative abilities of $\mathrm{Cu}_{2} \mathrm{O}$ and $\mathrm{Cu}_{3} \mathrm{~N}$ to stabilize the $\mathrm{Cu}(\mathrm{I})$ species was also observed due to an additional barrier against the $\mathrm{N}$ atoms diffusing from their original positions in the first layer of the support to the catalyst surface. Hence, the $\mathrm{N}$ atoms tend to be retained in their original positions, thus stabilizing the oxidation state of $\mathrm{Cu}$ in their vicinity.

a

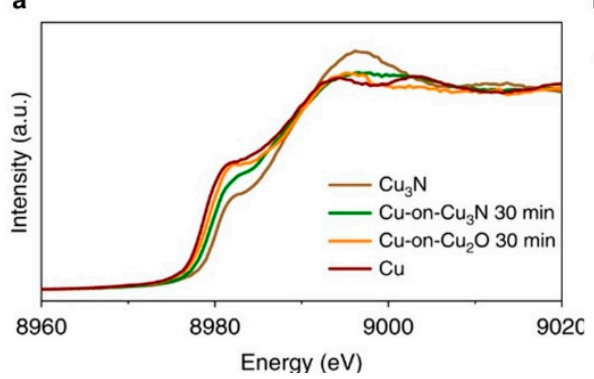

b

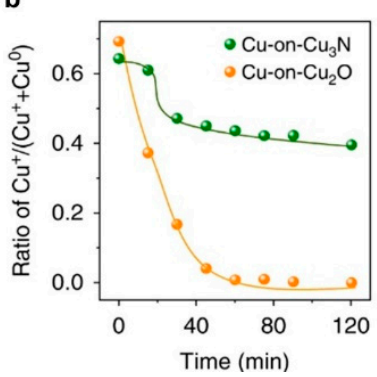

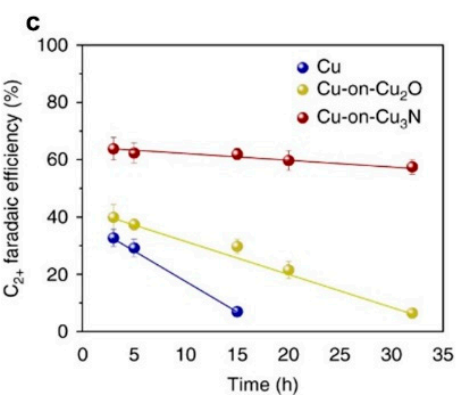

Figure 14. The effects of various support materials for a $\mathrm{Cu}$ catalyst: (a) in situ $\mathrm{Cu}$ K-edge spectra obtained during the initial $30 \mathrm{~min}$ for the supported catalysts $\mathrm{Cu}$-on- $\mathrm{Cu}_{3} \mathrm{~N}$ (green) and $\mathrm{Cu}$-on- $\mathrm{Cu}_{2} \mathrm{O}$ (orange), along with reference spectra for $\mathrm{Cu}$ (red) and $\mathrm{Cu}_{3} \mathrm{~N}$ (yellow); (b) the ratio of $\mathrm{Cu}^{+}$to reaction time at $-0.95 \mathrm{~V}$ vs. RHE; (c) the stability of $\mathrm{Cu}, \mathrm{Cu}-\mathrm{on}-\mathrm{Cu} \mathrm{O}_{2} \mathrm{O}$, and $\mathrm{Cu}-\mathrm{on}-\mathrm{Cu}_{3} \mathrm{~N}$ towards $\mathrm{C}_{2+}$ selectivity (reprinted with permission from ref. [119], copyright 2018, Springer Nature).

Another example of metal-stabilizing support material is that of the 3D ordered mesoporous Sn-Ti-O electrocatalysts, in, which the transfer of electron density from Ti to $\mathrm{Sn}$ has been shown to promote the dissociative adsorption of $\mathrm{COOH}^{*}$, thus preventing the reduction of $\mathrm{SnO}_{x}$ and the removal of oxygen atoms from the crystal lattice [121]. In addition, the use of oxidized $\mathrm{Cu}$ nanorods as a support for the Sn catalyst has been shown to provide increased performance stability along with only a negligible change in the resulting nanostructure [66].

\subsection{Single Atom Fixation}

Single-atom catalysts have been shown to be beneficial for providing dispersed active sites and fixing metal atoms within the support materials by complexation. In addition, the 
single-atom catalyst provides efficient intermediate stabilization and easy charge transfer. Fixation can expose the single metal atom to the reactants, assisted by the abundant coordination $\mathrm{N}$ sites and high electrical conductivity of the support material [122]. For example, the use of polymer-derived hollow $N$-doped porous carbon spheres (HNPCSs) as a support material, with cobalt (Co) as the metal center, has been shown to provide a high activity for $\mathrm{CO}$ production along with stable performance of $90 \% \mathrm{FE}$ at $-0.73 \mathrm{~V}$ for $10 \mathrm{~h}$. Hence, this $\mathrm{N}$-coordination strategy has been shown to maintain both $\mathrm{CO}$ production and the valence state of the Co sites. This ability to maintain the metal valence state during electrolysis is attributed to the electronic coupling between the metal and the conductive carbon support, which both enhances the $\mathrm{CO}_{2}$ affinity of the metal sites and facilitates the redistribution of electrons in the vicinity of the coordinating metal via adaptation of the geometrical structure [102,123]. For example, Gu et al. [102] examined the use of a Fe-doped ZIF-8-derived carbon framework in $\mathrm{CO}_{2}$ electroreduction to demonstrate that the conjugation of $\mathrm{Fe}^{3+}$ to the conductive carbon matrix generated an electronic coupling effect, which adjusted the $\mathrm{Fe}^{3+/ 2+}$-reduction potential to match the Fermi level of the carbon support upon application of an external bias [102]. This strong coupling effect can explain the stability of the $\mathrm{Fe}^{3+}$ species and the lack of redox chemistry on conjugated molecular sites during potential cycling [123]. The resulting stable $3^{+}$oxidation state of Fe has been observed using X-ray absorption spectroscopy (XAS) during electrolysis and has been shown to result in facile $\mathrm{CO}_{2}$ adsorption and $\mathrm{CO}$ desorption during $12 \mathrm{~h}$ of operation at an overpotential of $340 \mathrm{mV}$ even in a different electrolyte matrix [102].

In the case of the GDL-based flow cell, retention of the catalyst on the support material is of paramount importance to ensure a prolonged high $\mathrm{CO}_{2}$-reduction activity. However, material leaching has been often reported and results in a significant deterioration in the electrocatalytic activity. Hence, strategies have been developed for the design of robust catalysts with enhanced stability and minimal detachment of the electroactive species [124,125]. For example, the synthesis of a porous carbon membrane with interconnected nanofibers and hierarchical pores as a single nickel atom (NiSA) support is shown schematically in Figure 15a, and the results of long-term stability testing in a GDL-based flow cell (black line represents current density and red squares for $\mathrm{CO}$ production Faradaic Efficiency) are presented in Figure 15b. Thus, long-term performance stability of $80 \% \mathrm{FE}_{\mathrm{CO}}$ for $120 \mathrm{~h}$ was observed at a current density of $300 \mathrm{~mA} \mathrm{~cm}^{-2}$ in the flow cell [124]. In addition, XPS, XRD and XANES analyses were used to conclude that the Ni single atoms were preserved (i.e., not agglomerated) in the low valence state.
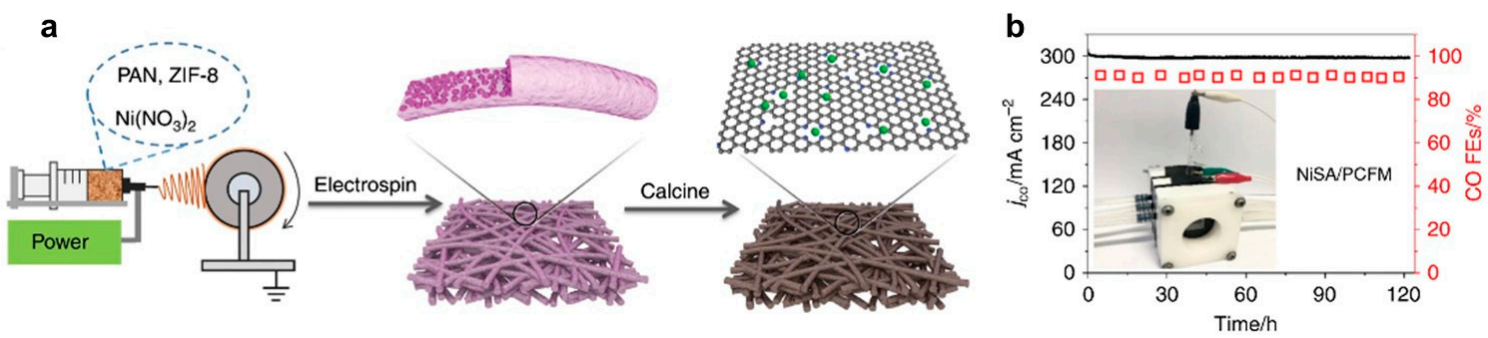

Figure 15. A robust Ni single atom supported on porous carbon fibers membrane (NiSA/PCFM): (a) schematic synthesis; (b) the results of current density (black line) and FE (red squares) for CO production long-term stability tests in a GDL-based flow cell at $-1.0 V_{\text {RHE }}$ (reproduced with permission from ref. [124], copyright 2020, Springer Nature).

\subsection{Electrode, Electrolyte and Process Modifications}

Process modification strategies are also important for maintaining the stability of catalyst performance. For example, the application of two-step cyclic electrolysis has been shown to maintain a constant current density during formate production on a $\mathrm{PdAg}$ alloy with an FE of $97.8 \%$ for up to $45 \mathrm{~h}$ of continuous operation (Figure 16a) [58]. As demonstrated in Figure 16b, this prolonged sustained current density was achieved via 
a programmed cycle consisting of a reduction step ( $-0.18 \mathrm{~V}$ vs. RHE for $590 \mathrm{~s})$ and an oxidation step (1.22 V vs. RHE for $10 \mathrm{~s}$ ) for 270 cycles. As shown in Figure 16c, this method allowed the initial current density value to be fully maintained along with a high FE for formate by careful consideration of the oxidation period in order to completely eliminate $\mathrm{CO}$ from the surface, i.e., by decoupling the formate production from $\mathrm{CO}$ adsorption. However, determining the optimum time for each step requires the process to operate at the highest possible energy efficiency. More recently, a similar procedure was used to achieve $86 \%$ recovery of $\mathrm{CH}_{4}$ production by sweeping a deactivated Pt electrode up to $0.3 \mathrm{~V}$ to allow the back-oxidation of $\mathrm{CO}$ to $\mathrm{CO}_{2}$ to occur simultaneously [126]. In addition to mitigating catalyst poisoning by intermediates, the potential cycling strategy has been shown to eliminate the deposition of metal impurities on the step/kink sites of the catalyst, thus recovering the deactivated electrode and enabling a prolonged catalyst lifetime [127].
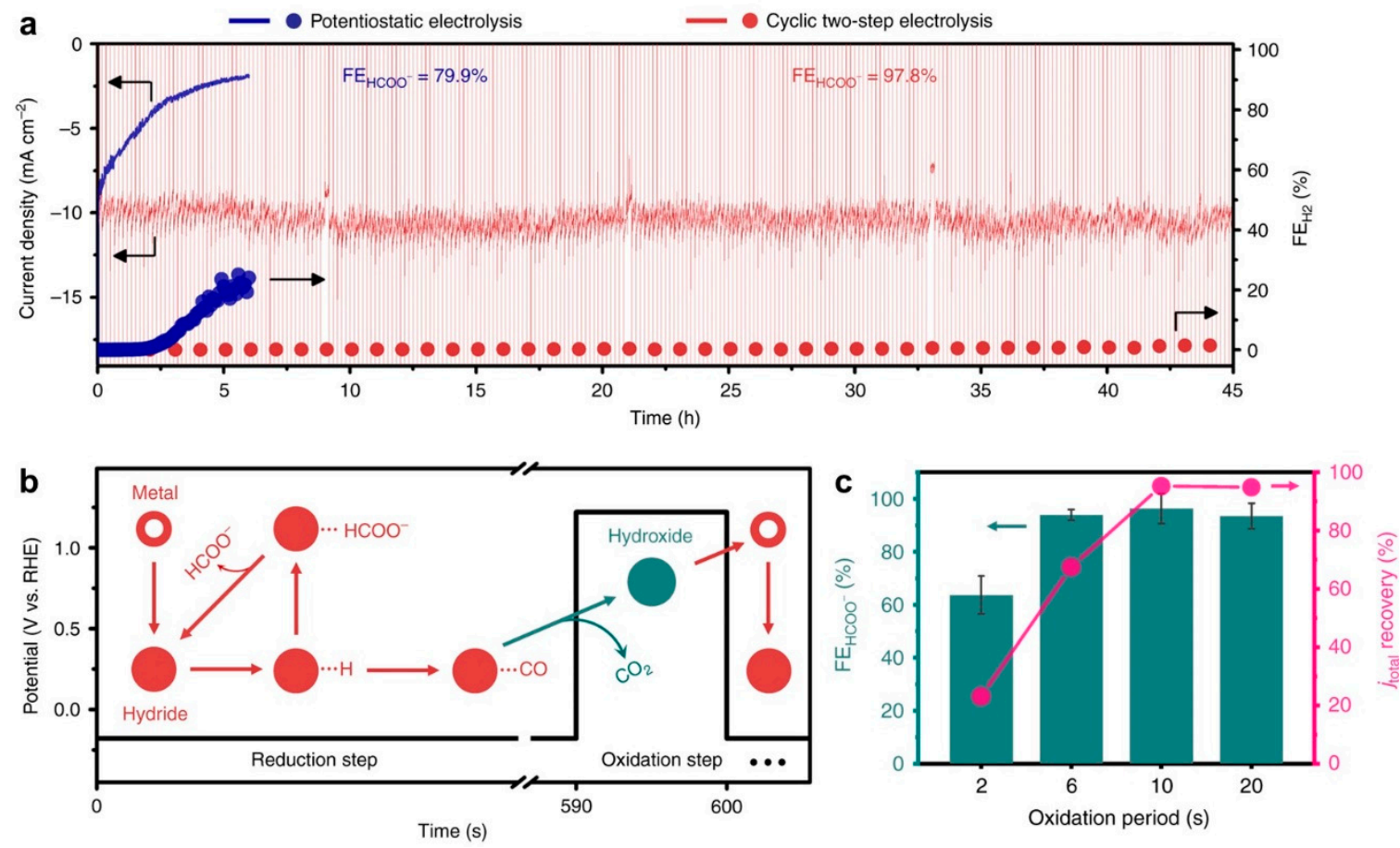

Figure 16. (a) Comparison of the cyclic two-step electrolysis and potentiostatic electrolysis in terms of current density and product selectivity; (b) potential program and reaction scheme for the cyclic two-step electrolysis; (c) the dependence of the current density recovery $\left(j_{\text {total }}\right)$ and the $\mathrm{HCOO}^{-} \mathrm{FE}$ on the oxidation period (reproduced with permission from ref. [58], copyright 2019, Springer Nature).

As discussed previously, the use of the GDL electrode suffers from gradually reduced hydrophobicity and consequent flooding behavior. The idea of maintaining the hydrophobicity of the gas diffusion side along with a good balance of the three-phase boundary has been recently developed. In 2018, the Sargent group demonstrated the flooding-resistant electrode structure composed of graphite, carbon NPs, Cu catalyst, and PTFE membrane shown in Figure 17a, with stable performance for up to $150 \mathrm{~h}$ [94]. In this setup, the GDE hydrophobicity was ensured by utilizing a PTFE membrane as a more stable hydrophobic gas diffusion layer, thus inhibiting excessive water infiltration to the gas chamber. To uniformly distribute the current density over the geometric surface, carbon black NPs were spray-coated on top of the $\mathrm{Cu}$ catalyst layer, and a graphite layer was added as the overall support and current collector. 

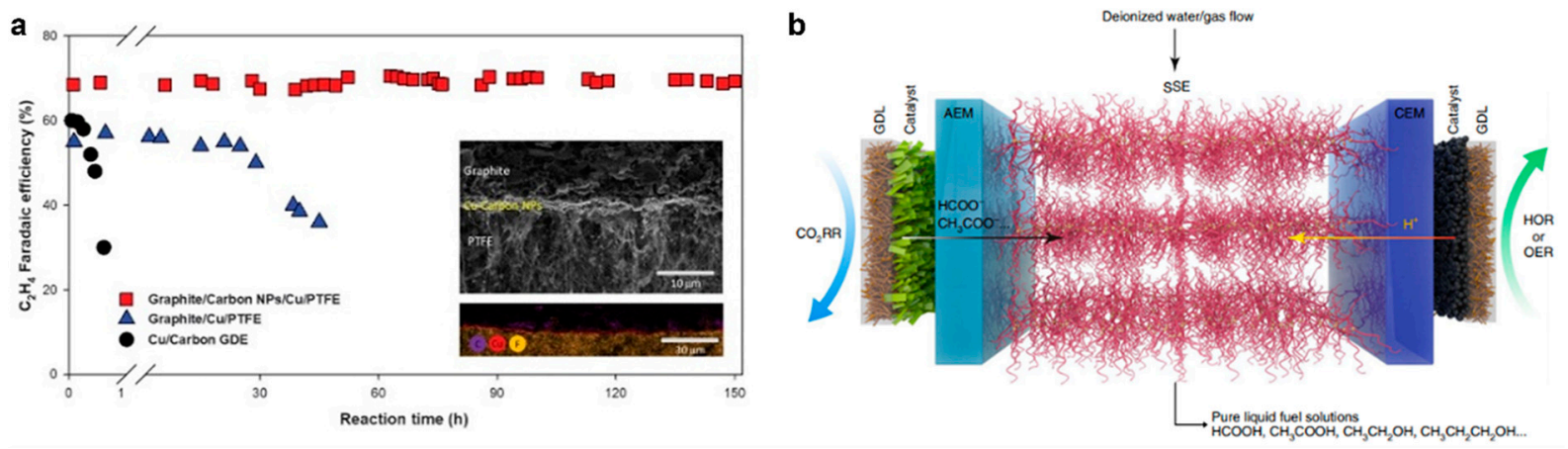

Figure 17. (a) A comparison of the selectivity towards $\mathrm{CO}_{2}$ reduction to ethylene in $7 \mathrm{M} \mathrm{KOH}$ and the stability of a graphite/carbon NPs/Cu/PTFE electrode and a traditional carbon-based GDE. The insets show the cross-sectional SEM and energy-dispersive X-ray spectroscopy mapping of the sample after $150 \mathrm{~h}$ of continuous operation (reproduced with permission from ref. [94], copyright 2018, AAAS); (b) a schematic illustration of a $\mathrm{CO}_{2}$ reduction cell with a solid electrolyte. The SSE is either an anion or cation conductor (reproduced with permission from ref. [45], copyright 2019, Springer Nature).

In another approach, the Wang group successfully demonstrated an all-solid-state electrolyte-based reaction system, as shown in Figure 17b [45]. The reactor was supplied with humidified $\mathrm{CO}_{2}$ gas to facilitate $\mathrm{CO}_{2}$ mass transport on the cathode side, while $0.5 \mathrm{M}$ $\mathrm{H}_{2} \mathrm{SO}_{4}$ was circulated on the anode side as the counter water oxidation. The cathode and anode were entirely separated by positioning the solid-state electrolyte at the center, with the anion-exchange membrane (EM) and the cation-exchange membrane (CEM) on either side. Thus, the electrical field drives the product $\left(\mathrm{HCOO}^{-}\right)$through the EM towards the solid-electrolyte channel, where it is balanced by $\mathrm{H}^{+}$ions produced by water oxidation at the anode and subsequently released by a slow stream of deionized water or a flow of humidified inert gas. A total operation time of $100 \mathrm{~h}$ and stable generation of $0.1 \mathrm{M}$ $\mathrm{HCOOH}$ was obtained with negligible degradation in selectivity and activity. Moreover, this performance was improved to nearly $100 \mathrm{wt} \%$ pure formic acid by using a dry inert gas carrier, thus eliminating the need for purification [29]. Notwithstanding the remarkable performance of this reactor design, further improvements are still needed in order to increase the efficiency of the cell along with the stability of the solid electrolyte and ion exchange membranes under low water conditions, thus preventing product crossover [29].

To address the mechanical stability problems encountered when utilizing the GDE, a strategy for improving the attachment of the catalyst material to porous support was reported by Hou et al. [128]. Here, photonic curing was performed as a pretreatment step to apply a mild sintering effect to the $\mathrm{Cu}$ catalyst $(\mathrm{Cu}-\mathrm{NW})$ in order to locally confine the reactants to their points of contact with the catalyst. This approach can also remove the surfactants, which are used to control the catalyst size and morphology during synthesis. In this manner, any loss of catalyst from the support during massive gas evolution can be prevented.

\section{Conclusions}

Many efforts have been devoted to achieving a stable $\mathrm{CO}_{2}$ electroreduction performance in terms of catalyst design, electrode engineering, and system-level modification. The main issues and solutions were discussed in detail in the present review and are summarized in the following paragraphs.

Among the issues that hinder the mass production of electrochemical $\mathrm{CO}_{2}$ reduction, the biggest issue is low productivity and difficulty in product separation due to low current density and Faraday efficiency. In order to solve this at the device level, studies are being conducted to optimize the membrane and device structure. Through the introduction of a microfluidic cell, zero-gap electrolyzer, multilayer electrolyzer stack, etc., to reduce the amount of electrolyte used and accelerate the $\mathrm{CO}_{2}$ conversion reaction rate, mass production is getting closer to reality. In terms of the process, various techno-economic 
analyses have been performed, indicating that formic acid can be commercialized under certain conditions even with the current technology level. However, many lab-scale studies ignore the impact of separation processes that separate final products from electrolytes or unreacted gases. In recent studies, it was found that the separation process occupies a significant part of the operating cost, and overall process integration is being performed for this part. In order to replace the conventional petrochemical industry with electrochemical $\mathrm{CO}_{2}$-reduction processes in the future, electric energy should be supplied by renewable energy sources such as wind and solar. Recent studies have been increasing attention to the large-scale electrochemical reduction of $\mathrm{CO}_{2}$ in government sectors through analysis of economic feasibility and life-cycle assessment according to energy sources.

The catalyst poisoning behavior resulting from a high intermediate binding energy is alleviated by utilizing alloy electrocatalysts that are more resistant to poisoning and is completely solved by the introduction of a cyclic two-step electrolytic process in, which the reduction and oxidation potentials are applied periodically. In addition, the degradation in activity caused by metal impurities can be controlled by using a purified electrolyte. In particular, the use of support material and single-atom fixation provide intriguing strategies for addressing catalyst degradation caused by the restructuring and compositional changes and, thus, retaining the particle size, morphology, and valency state. In addition, the use of a membrane or hydrophobic electrode has been shown to minimize flooding behavior, thus extending the operation time to hundreds of hours.

For commercialization of the $\mathrm{CO}_{2}$-reduction reaction, many advances are still needed in order to address the prevailing issues and disadvantages and enable continuous operation along with an optimal cost-result balance. While many studies have outlined approaches to tunable catalyst selectivity and the optimization of reaction conditions and electrolyzer design for achieving certain products, the long-term operating performance has been often omitted. Hence, further studies must include a more comprehensive study in terms of performance stability, including experimental results and characterization of the catalyst before, during, and after the electrolysis in order to identify the real-time degradation mechanisms.

Author Contributions: Conceptualization, J.N. and C.W.L.; writing-original draft preparation, S.P. and D.T.W.; writing - review and editing, J.N. and C.W.L. All authors have read and agreed to the published version of the manuscript.

Funding: This work was supported by the National Research Foundation of Korea (NRF) Grant funded by the Korean Government (MSIT) (NRF-2020R1F1A1066080, NRF-2020R1C1C1010963). This work was supported by the "Carbon to X Project" (NRF-2020M3H7A1098266, NRF-2020M3H7A1098229) through the National Research Foundation (NRF) funded by the Ministry of Science and ICT, Republic of Korea. This work was supported by the Ewha Womans University Research Grant of 2020.

Data Availability Statement: Data presented in this study are available on request from the corresponding author.

Conflicts of Interest: The authors declare no conflict of interest.

\section{References}

1. Gaulin, N.; Le Billon, P. Climate change and fossil fuel production cuts: Assessing global supply-side constraints and policy implications. Clim. Policy 2020, 20, 888-901. [CrossRef]

2. Rahaman, M.; Dutta, A.; Zanetti, A.; Broekmann, P. Electrochemical Reduction of $\mathrm{CO}_{2}$ into Multicarbon Alcohols on Activated Cu Mesh Catalysts: An Identical Location (IL) Study. ACS Catal. 2017, 7, 7946-7956. [CrossRef]

3. Lee, C.W.; Hong, J.S.; Yang, K.D.; Jin, K.; Lee, J.H.; Ahn, H.-Y.; Seo, H.; Sung, N.-E.; Nam, K.T. Selective Electrochemical Production of Formate from Carbon Dioxide with Bismuth-Based Catalysts in an Aqueous Electrolyte. ACS Catal. 2018, 8, 931-937. [CrossRef]

4. Lee, C.W.; Shin, S.-J.; Jung, H.; Nguyen, D.L.T.; Lee, S.Y.; Lee, W.H.; Won, D.H.; Kim, M.G.; Oh, H.-S.; Jang, T.; et al. Metal-Oxide Interfaces for Selective Electrochemical C-C Coupling Reactions. ACS Energy Lett. 2019, 4, 2241-2248. [CrossRef]

5. Zhao, K.; Nie, X.; Wang, H.; Chen, S.; Quan, X.; Yu, H.; Choi, W.; Zhang, G.; Kim, B.; Chen, J.G. Selective electroreduction of CO 2 to acetone by single copper atoms anchored on N-doped porous carbon. Nat. Commun. 2020, 11, 2455. [CrossRef] 
6. $\quad$ Lin, S.-C.; Chang, C.-C.; Chiu, S.-Y.; Pai, H.-T.; Liao, T.-Y.; Hsu, C.-S.; Chiang, W.-H.; Tsai, M.-K.; Chen, H.M. Operando timeresolved X-ray absorption spectroscopy reveals the chemical nature enabling highly selective $\mathrm{CO}_{2}$ reduction. Nat. Commun. 2020, 11, 3525. [CrossRef]

7. Na, J.; Seo, B.; Kim, J.; Lee, C.W.; Lee, H.; Hwang, Y.J.; Min, B.K.; Lee, D.K.; Oh, H.-S.; Lee, U. General technoeconomic analysis for electrochemical coproduction coupling carbon dioxide reduction with organic oxidation. Nat. Commun. 2019, 10, 5193. [CrossRef] [PubMed]

8. Bushuyev, O.S.; De Luna, P.; Dinh, C.T.; Tao, L.; Saur, G.; van de Lagemaat, J.; Kelley, S.O.; Sargent, E.H. What Should We Make with $\mathrm{CO}_{2}$ and How Can We Make It? Joule 2018, 2, 825-832. [CrossRef]

9. Jouny, M.; Luc, W.W.; Jiao, F. General Techno-Economic Analysis of $\mathrm{CO}_{2}$ Electrolysis Systems. Ind. Eng. Chem. Res. 2018, 57, 2165-2177. [CrossRef]

10. Verma, S.; Kim, B.; Jhong, H.-R.; Ma, S.; Kenis, P.J.A. A Gross-Margin Model for Defining Technoeconomic Benchmarks in the Electroreduction of $\mathrm{CO}_{2}$. ChemSusChem 2016, 9, 1972-1979. [CrossRef] [PubMed]

11. Verma, S.; Lu, S.; Kenis, P.J.A. Co-electrolysis of $\mathrm{CO}_{2}$ and glycerol as a pathway to carbon chemicals with improved technoeconomics due to low electricity consumption. Nat. Energy 2019, 4, 466-474. [CrossRef]

12. Sánchez, O.G.; Birdja, Y.Y.; Bulut, M.; Vaes, J.; Breugelmans, T.; Pant, D. Recent advances in industrial $\mathrm{CO}_{2}$ electroreduction. Curr. Opin. Green Sustain. Chem. 2019, 16, 47-56. [CrossRef]

13. Kim, K.; Lee, W.H.; Na, J.; Hwang, Y.J.; Oh, H.-S.; Lee, U. Data-driven pilot optimization for electrochemical CO mass production. J. Mater. Chem. A 2020, 8, 16943-16950. [CrossRef]

14. Liang, S.; Altaf, N.; Huang, L.; Gao, Y.; Wang, Q. Electrolytic cell design for electrochemical $\mathrm{CO}_{2}$ reduction. J. CO2 Util. 2020, 35 , 90-105. [CrossRef]

15. Higgins, D.C.; Hahn, C.; Xiang, C.; Jaramillo, T.F.; Weber, A.Z. Gas-Diffusion Electrodes for Carbon Dioxide Reduction: A New Paradigm. ACS Energy Lett. 2019, 4, 317-324. [CrossRef]

16. Ren, W.; Zhao, C. Paths towards enhanced electrochemical $\mathrm{CO}_{2}$ reduction. Natl. Sci. Rev. 2020, 7, 7-9. [CrossRef]

17. Garg, S.; Li, M.; Weber, A.Z.; Ge, L.; Li, L.; Rudolph, V.; Wang, G.; Rufford, T.E. Advances and challenges in electrochemical CO 2 reduction processes: An engineering and design perspective looking beyond new catalyst materials. J. Mater. Chem. A 2020, 8 , 1511-1544. [CrossRef]

18. Lin, R.; Guo, J.; Li, X.; Patel, P.; Seifitokaldani, A. Electrochemical Reactors for $\mathrm{CO}_{2}$ Conversion. Catalysts 2020, 10, 473. [CrossRef]

19. Ramdin, M.; Morrison, A.R.T.; de Groen, M.; van Haperen, R.; de Kler, R.; van den Broeke, L.J.P.; Trusler, J.P.M.; de Jong, W.; Vlugt, T.J.H. High Pressure Electrochemical Reduction of $\mathrm{CO}_{2}$ to Formic Acid/Formate: A Comparison between Bipolar Membranes and Cation Exchange Membranes. Ind. Eng. Chem. Res. 2019, 58, 1834-1847. [CrossRef]

20. Yan, Z.; Zhu, L.; Li, Y.C.; Wycisk, R.J.; Pintauro, P.N.; Hickner, M.A.; Mallouk, T.E. The balance of electric field and interfacial catalysis in promoting water dissociation in bipolar membranes. Energy Environ. Sci. 2018, 11, 2235-2245. [CrossRef]

21. Hernández-Pagán, E.A.; Vargas-Barbosa, N.M.; Wang, T.; Zhao, Y.; Smotkin, E.S.; Mallouk, T.E. Resistance and polarization losses in aqueous buffer-membrane electrolytes for water-splitting photoelectrochemical cells. Energy Environ. Sci. 2012, 5, 7582-7589. [CrossRef]

22. Li, Y.C.; Zhou, D.; Yan, Z.; Gonçalves, R.H.; Salvatore, D.A.; Berlinguette, C.P.; Mallouk, T.E. Electrolysis of $\mathrm{CO}_{2}$ to Syngas in Bipolar Membrane-Based Electrochemical Cells. ACS Energy Lett. 2016, 1, 1149-1153. [CrossRef]

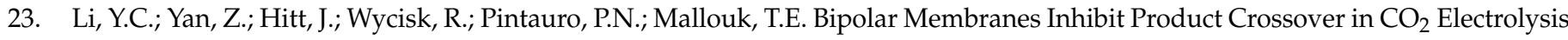
Cells. Adv. Sustain. Syst. 2018, 2, 1700187. [CrossRef]

24. Liu, Z.; Masel, R.I.; Chen, Q.; Kutz, R.; Yang, H.; Lewinski, K.; Kaplun, M.; Luopa, S.; Lutz, D.R. Electrochemical generation of syngas from water and carbon dioxide at industrially important rates. J. CO2 Util. 2016, 15, 50-56. [CrossRef]

25. Kutz, R.B.; Chen, Q.; Yang, H.; Sajjad, S.D.; Liu, Z.; Masel, I.R. Sustainion Imidazolium-Functionalized Polymers for Carbon Dioxide Electrolysis. Energy Technol. 2017, 5, 929-936. [CrossRef]

26. Liu, Z.; Yang, H.; Kutz, R.; Masel, R.I. $\mathrm{CO}_{2}$ Electrolysis to $\mathrm{CO}$ and $\mathrm{O}_{2}$ at High Selectivity, Stability and Efficiency Using Sustainion Membranes. J. Electrochem. Soc. 2018, 165, J3371-J3377. [CrossRef]

27. Weng, L.-C.; Bell, A.T.; Weber, A.Z. Towards membrane-electrode assembly systems for $\mathrm{CO}_{2}$ reduction: A modeling study. Energy Environ. Sci. 2019, 12, 1950-1968. [CrossRef]

28. Spurgeon, J.M.; Kumar, B. A comparative technoeconomic analysis of pathways for commercial electrochemical $\mathrm{CO}_{2}$ reduction to liquid products. Energy Environ. Sci. 2018, 11, 1536-1551. [CrossRef]

29. Fan, L.; Xia, C.; Zhu, P.; Lu, Y.; Wang, H. Electrochemical $\mathrm{CO}_{2}$ reduction to high-concentration pure formic acid solutions in an all-solid-state reactor. Nat. Commun. 2020, 11, 3633. [CrossRef]

30. Rumayor, M.; Dominguez-Ramos, A.; Perez, P.; Irabien, A. A techno-economic evaluation approach to the electrochemical reduction of CO2 for formic acid manufacture. J. CO2 Util. 2019, 34, 490-499. [CrossRef]

31. Salvatore, D.A.; Weekes, D.M.; He, J.; Dettelbach, K.E.; Li, Y.C.; Mallouk, T.E.; Berlinguette, C.P. Electrolysis of Gaseous $\mathrm{CO}_{2}$ to $\mathrm{CO}$ in a Flow Cell with a Bipolar Membrane. ACS Energy Lett. 2018, 3, 149-154. [CrossRef]

32. McDonald, M.B.; Ardo, S.; Lewis, N.S.; Freund, M.S. Use of Bipolar Membranes for Maintaining Steady-State pH Gradients in Membrane-Supported, Solar-Driven Water Splitting. ChemSusChem 2014, 7, 3021-3027. [CrossRef]

33. Weekes, D.M.; Salvatore, D.A.; Reyes, A.; Huang, A.; Berlinguette, C.P. Electrolytic $\mathrm{CO}_{2}$ Reduction in a Flow Cell. Acc. Chem. Res. 2018, 51, 910-918. [CrossRef] 
34. Yang, H.; Kaczur, J.J.; Sajjad, S.D.; Masel, R.I. Performance and long-term stability of $\mathrm{CO}_{2}$ conversion to formic acid using a three-compartment electrolyzer design. J. CO2 Util. 2020, 42, 101349. [CrossRef]

35. Lee, J.; Lim, J.; Roh, C.-W.; Whang, H.S.; Lee, H. Electrochemical $\mathrm{CO}_{2}$ reduction using alkaline membrane electrode assembly on various metal electrodes. J. CO2 Util. 2019, 31, 244-250. [CrossRef]

36. Xiang, H.; Rasul, S.; Hou, B.; Portoles, J.; Cumpson, P.; Yu, E.H. Copper-Indium Binary Catalyst on a Gas Diffusion Electrode for High-Performance $\mathrm{CO}_{2}$ Electrochemical Reduction with Record CO Production Efficiency. ACS Appl. Mater. Interfaces 2020, 12, 601-608. [CrossRef]

37. Lu, X.; Leung, D.Y.C.; Wang, H.; Maroto-Valer, M.M.; Xuan, J. A pH-differential dual-electrolyte microfluidic electrochemical cells for $\mathrm{CO}_{2}$ utilization. Renew. Energy 2016, 95, 277-285. [CrossRef]

38. Lv, J.-J.; Jouny, M.; Luc, W.; Zhu, W.; Zhu, J.-J.; Jiao, F. A Highly Porous Copper Electrocatalyst for Carbon Dioxide Reduction. Adv. Mater. 2018, 30, e1803111. [CrossRef]

39. Lu, X.; Leung, D.Y.; Wang, H.; Xuan, J. A high performance dual electrolyte microfluidic reactor for the utilization of $\mathrm{CO}_{2}$. Appl. Energy 2017, 194, 549-559. [CrossRef]

40. Lee, W.H.; Ko, Y.-J.; Choi, Y.; Lee, S.Y.; Choi, C.H.; Hwang, Y.J.; Min, B.K.; Strasser, P.; Oh, H.-S. Highly selective and scalable CO 2 to CO-Electrolysis using coral-nanostructured Ag catalysts in zero-gap configuration. Nano Energy 2020, 76, 105030. [CrossRef]

41. Delafontaine, L.; Asset, T.; Atanassov, P. Metal-Nitrogen-Carbon Electrocatalysts for $\mathrm{CO}_{2}$ Reduction towards Syngas Generation. ChemSusChem 2020, 13, 1688-1698. [CrossRef]

42. Endrődi, B.; Kecsenovity, E.; Samu, A.A.; Darvas, F.; Jones, R.V.; Török, V.; Danyi, A.; Janáky, C. Multilayer Electrolyzer Stack Converts Carbon Dioxide to Gas Products at High Pressure with High Efficiency. ACS Energy Lett. 2019, 4, 1770-1777. [CrossRef]

43. De Mot, B.; Ramdin, M.; Hereijgers, J.; Vlugt, T.J.H.; Breugelmans, T. Direct Water Injection in Catholyte-Free Zero-Gap Carbon Dioxide Electrolyzers. ChemElectroChem 2020, 7, 3839-3843. [CrossRef]

44. Ju, H.; Kaur, G.; Kulkarni, A.P.; Giddey, S. Challenges and trends in developing technology for electrochemically reducing $\mathrm{CO}_{2}$ in solid polymer electrolyte membrane reactors. J. CO2 Util. 2019, 32, 178-186. [CrossRef]

45. Xia, C.; Zhu, P.; Jiang, Q.; Pan, Y.; Liang, W.; Stavitski, E.; Alshareef, H.N.; Wang, H. Continuous production of pure liquid fuel solutions via electrocatalytic $\mathrm{CO}_{2}$ reduction using solid-electrolyte devices. Nat. Energy 2019, 4, 776-785. [CrossRef]

46. IRENA. Renewable Power Generation Costs in 2019; IRENA: Abu Dhabi, United Arab Emirates, 2020.

47. Song, Y.; Zhang, X.; Xie, K.; Wang, G.; Bao, X. High-Temperature $\mathrm{CO}_{2}$ Electrolysis in Solid Oxide Electrolysis Cells: Developments, Challenges, and Prospects. Adv. Mater. 2019, 31, e1902033. [CrossRef]

48. Mohammadi, A.; Mehrpooya, M. A comprehensive review on coupling different types of electrolyzer to renewable energy sources. Energy 2018, 158, 632-655. [CrossRef]

49. Cheng, W.-H.; Richter, M.H.; Sullivan, I.; Larson, D.M.; Xiang, C.; Brunschwig, B.S.; Atwater, H.A. $\mathrm{CO}_{2}$ Reduction to CO with 19\% Efficiency in a Solar-Driven Gas Diffusion Electrode Flow Cell under Outdoor Solar Illumination. ACS Energy Lett. 2020, 5, 470-476. [CrossRef]

50. Chatterjee, S.; Griego, C.; Hart, J.L.; Li, Y.; Taheri, M.L.; Keith, J.A.; Snyder, J.D. Free Standing Nanoporous Palladium Alloys as CO Poisoning Tolerant Electrocatalysts for the Electrochemical Reduction of $\mathrm{CO}_{2}$ to Formate. ACS Catal. 2019, 9, 5290-5301. [CrossRef]

51. Zhou, Y.; Zhou, R.; Zhu, X.; Han, N.; Song, B.; Liu, T.; Hu, G.; Li, Y.; Lu, J.; Li, Y. Mesoporous PdAg Nanospheres for Stable Electrochemical $\mathrm{CO}_{2}$ Reduction to Formate. Adv. Mater. 2020, 32, e2000992. [CrossRef]

52. Pavesi, D.; Ali, F.S.M.; Anastasiadou, D.; Kallio, T.; Figueiredo, M.C.; Gruter, G.-J.M.; Koper, M.T.M.; Schouten, K.J.P. CO 2 electroreduction on bimetallic Pd-In nanoparticles. Catal. Sci. Technol. 2020, 10, 4264-4270. [CrossRef]

53. Weng, Z.; Zhang, X.; Wu, Y.; Huo, S.; Jiang, J.; Liu, W.; He, G.; Liang, Y.; Wang, H. Self-Cleaning Catalyst Electrodes for Stabilized $\mathrm{CO}_{2}$ Reduction to Hydrocarbons. Angew. Chem. Int. Ed. 2017, 56, 13135-13139. [CrossRef]

54. Wang, Y.; Cao, L.; Libretto, N.J.; Li, X.; Li, C.; Wang, Y.; He, C.; Lee, J.; Gregg, J.; Zong, H.; et al. Ensemble Effect in Bimetallic Electrocatalysts for $\mathrm{CO}_{2}$ Reduction. J. Am. Chem. Soc. 2019, 141, 16635-16642. [CrossRef]

55. Dutta, A.; Morstein, C.E.; Rahaman, M.; López, A.C.; Broekmann, P. Beyond Copper in $\mathrm{CO}_{2}$ Electrolysis: Effective Hydrocarbon Production on Silver-Nanofoam Catalysts. ACS Catal. 2018, 8, 8357-8368. [CrossRef]

56. Akhade, S.A.; Luo, W.; Nie, X.; Bernstein, N.J.; Asthagiri, A.; Janik, M.J. Poisoning effect of adsorbed $\mathrm{CO}^{\text {during }} \mathrm{CO}_{2}$ electroreduction on late transition metals. Phys. Chem. Chem. Phys. 2014, 16, 20429-20435. [CrossRef]

57. Koper, M.T.; Van Santen, R.R. Electric field effects on CO and NO adsorption at the Pt(111) surface. J. Electroanal. Chem. 1999, 476, 64-70. [CrossRef]

58. Lee, C.W.; Cho, N.H.; Nam, K.T.; Hwang, Y.J.; Min, B.K. Cyclic two-step electrolysis for stable electrochemical conversion of carbon dioxide to formate. Nat. Commun. 2019, 10, 3919. [CrossRef]

59. Jiang, S.; Klingan, K.; Pasquini, C.; Dau, H. New aspects of operando Raman spectroscopy applied to electrochemical $\mathrm{CO}_{2}$ reduction on Cu foams. J. Chem. Phys. 2019, 150, 041718. [CrossRef]

60. Hori, Y.; Konishi, H.; Futamura, T.; Murata, A.; Koga, O.; Sakurai, H.; Oguma, K. "Deactivation of copper electrode" in electrochemical reduction of $\mathrm{CO}_{2}$. Electrochim. Acta 2005, 50, 5354-5369. [CrossRef]

61. Lucas, F.W.S.; Lima, F.H.B. Electrodeposited Tin-Antimony Alloys as Novel Electrocatalysts for Selective and Stable Carbon Dioxide Reduction to Formate. ChemElectroChem 2020, 7, 3733-3742. [CrossRef] 
62. Lum, Y.; Kwon, Y.; Lobaccaro, P.; Chen, L.; Clark, E.L.; Bell, A.T.; Ager, J.W. Trace Levels of Copper in Carbon Materials Show Significant Electrochemical $\mathrm{CO}_{2}$ Reduction Activity. ACS Catal. 2016, 6, 202-209. [CrossRef]

63. Bai, X.; Chen, W.; Zhao, C.; Li, S.; Song, Y.; Ge, R.; Wei, W.; Sun, Y. Exclusive Formation of Formic Acid from $\mathrm{CO}_{2}$ Electroreduction by a Tunable Pd-Sn Alloy. Angew. Chem. 2017, 129, 12387-12391. [CrossRef]

64. Choi, W.; Won, D.H.; Hwang, Y.J. Catalyst design strategies for stable electrochemical $\mathrm{CO}_{2}$ reduction reaction. J. Mater. Chem. A 2020, 8, 15341-15357. [CrossRef]

65. Won, D.H.; Shin, H.; Chung, M.W.; Jung, H.; Chae, K.H.; Oh, H.-S.; Hwang, Y.J.; Min, B.K. Achieving tolerant CO 2 electroreduction catalyst in real water matrix. Appl. Catal. B Environ. 2019, 258, 117961. [CrossRef]

66. Yoo, C.J.; Dong, W.J.; Park, J.Y.; Lim, J.W.; Kim, S.; Choi, K.S.; Ngome, F.O.O.; Choi, S.-Y.; Lee, J.-L. Compositional and Geometrical Effects of Bimetallic Cu-Sn Catalysts on Selective Electrochemical $\mathrm{CO}_{2}$ Reduction to CO. ACS Appl. Energy Mater. 2020, 3, 4466-4473. [CrossRef]

67. Alfath, M.; Lee, C.W. Recent Advances in the Catalyst Design and Mass Transport Control for the Electrochemical Reduction of Carbon Dioxide to Formate. Catalysts 2020, 10, 859. [CrossRef]

68. Ouyang, R.; Liu, J.-X.; Li, W.-X. Atomistic Theory of Ostwald Ripening and Disintegration of Supported Metal Particles under Reaction Conditions. J. Am. Chem. Soc. 2013, 135, 1760-1771. [CrossRef]

69. Zhang, A.; Liang, Y.; Li, H.; Zhang, B.; Liu, Z.; Chang, Q.; Zhang, H.; Zhu, C.-F.; Geng, Z.; Zhu, W.; et al. In-Situ Surface Reconstruction of InN Nanosheets for Efficient $\mathrm{CO}_{2}$ Electroreduction into Formate. Nano Lett. 2020, 20, 8229-8235. [CrossRef]

70. Zhong, H.; Qiu, Y.; Li, X.; Pan, L.; Zhang, H. Ordered cone-structured tin directly grown on carbon paper as efficient electrocatalyst for $\mathrm{CO}_{2}$ electrochemical reduction to formate. J. Energy Chem. 2021, 55, 236-243. [CrossRef]

71. Pan, F.; Yang, Y. Designing $\mathrm{CO}_{2}$ reduction electrode materials by morphology and interface engineering. Energy Environ. Sci. 2020, 13, 2275-2309. [CrossRef]

72. Dutta, A.; Montiel, I.Z.; Erni, R.; Kiran, K.; Rahaman, M.; Drnec, J.; Broekmann, P. Activation of bimetallic AgCu foam electrocatalysts for ethanol formation from $\mathrm{CO}_{2}$ by selective $\mathrm{Cu}$ oxidation/reduction. Nano Energy 2020, 68, 104331. [CrossRef]

73. Yang, H.; Huang, Y.; Deng, J.; Wu, Y.; Han, N.; Zha, C.; Li, L.; Li, Y. Selective electrocatalytic $\mathrm{CO}_{2}$ reduction enabled by $\mathrm{SnO}_{2}$ nanoclusters. J. Energy Chem. 2019, 37, 93-96. [CrossRef]

74. Huang, J.; Hörmann, N.; Oveisi, E.; Loiudice, A.; De Gregorio, G.L.; Andreussi, O.; Marzari, N.; Buonsanti, R. Potential-induced nanoclustering of metallic catalysts during electrochemical $\mathrm{CO}_{2}$ reduction. Nat. Commun. 2018, 9, 3117. [CrossRef]

75. Duan, Y.-X.; Meng, F.-L.; Liu, K.-H.; Yi, S.-S.; Li, S.-J.; Yan, J.-M.; Jiang, Q. Amorphizing of Cu Nanoparticles toward Highly Efficient and Robust Electrocatalyst for $\mathrm{CO}_{2}$ Reduction to Liquid Fuels with High Faradaic Efficiencies. Adv. Mater. 2018, 30, e1706194. [CrossRef] [PubMed]

76. Matsubu, J.C.; Yang, V.N.; Christopher, P. Isolated Metal Active Site Concentration and Stability Control Catalytic CO2 Reduction Selectivity. J. Am. Chem. Soc. 2015, 137, 3076-3084. [CrossRef] [PubMed]

77. Spoeri, C.; Kwan, J.T.H.; Bonakdarpour, A.; Wilkinson, D.P.; Strasser, P. The Stability Challenges of Oxygen Evolving Catalysts: Towards a Common Fundamental Understanding and Mitigation of Catalyst Degradation. Angew. Chem. Int. Ed. 2017, 56, 5994-6021. [CrossRef] [PubMed]

78. De Luna, P.; Quintero-Bermudez, R.; Dinh, C.-T.; Ross, M.B.; Bushuyev, O.S.; Todorović, P.; Regier, T.; Kelley, S.O.; Yang, P.; Sargent, E.H. Catalyst electro-redeposition controls morphology and oxidation state for selective carbon dioxide reduction. Nat. Catal. 2018, 1, 103-110. [CrossRef]

79. Andrews, E.M.; Flake, J.; Fang, Y. $\mathrm{CO}_{2}$ Electrocatalytic Reduction at Gold and Copper Electrodes: Role of Particle Size and Surface Chemistry. ECS Trans. 2015, 66, 67-70. [CrossRef]

80. Kauffman, D.R.; Thakkar, J.; Siva, R.; Matranga, C.; Ohodnicki, P.R.; Zeng, C.; Jin, R. Efficient Electrochemical CO $\mathrm{CO}_{2} \mathrm{Conversion}$ Powered by Renewable Energy. ACS Appl. Mater. Interfaces 2015, 7, 15626-15632. [CrossRef]

81. Mistry, H.; Reske, R.; Zeng, Z.; Zhao, Z.-J.; Greeley, J.; Strasser, P.; Cuenya, B.R. Exceptional Size-Dependent Activity Enhancement in the Electroreduction of $\mathrm{CO}_{2}$ over Au Nanoparticles. J. Am. Chem. Soc. 2014, 136, 16473-16476. [CrossRef]

82. Li, X.; Wang, S.; Li, L.; Sun, Y.; Xie, Y. Progress and Perspective for In Situ Studies of $\mathrm{CO}_{2}$ Reduction. J. Am. Chem. Soc. 2020, 142, 9567-9581. [CrossRef] [PubMed]

83. Fiordaliso, E.M.; Sharafutdinov, I.; Carvalho, H.W.P.; Grunwaldt, J.-D.; Hansen, T.W.; Chorkendorff, I.; Wagner, J.B.; Damsgaard, C.D. Intermetallic $\mathrm{GaPd}_{2}$ Nanoparticles on $\mathrm{SiO}_{2}$ for Low-Pressure $\mathrm{CO}_{2}$ Hydrogenation to Methanol: Catalytic Performance and In Situ Characterization. ACS Catal. 2015, 5, 5827-5836. [CrossRef]

84. Luc, W.; Collins, C.; Wang, S.; Xin, H.; He, K.; Kang, Y.; Jiao, F. Ag-Sn bimetallic catalyst with a core-shell structure for $\mathrm{CO}_{2}$ reduction. J. Am. Chem. Soc. 2017, 139, 1885-1893. [CrossRef] [PubMed]

85. Mistry, H.; Varela, A.S.; Bonifacio, C.S.; Zegkinoglou, I.; Sinev, I.; Choi, Y.W.; Kisslinger, K.; Stach, E.A.; Yang, J.C.; Strasser, P.; et al. Highly selective plasma-activated copper catalysts for carbon dioxide reduction to ethylene. Nat. Commun. 2016, 7, 12123. [CrossRef]

86. Gao, D.; Zegkinoglou, I.; Divins, N.J.; Scholten, F.; Sinev, I.; Grosse, P.; Cuenya, B.R. Plasma-Activated Copper Nanocube Catalysts for Efficient Carbon Dioxide Electroreduction to Hydrocarbons and Alcohols. ACS Nano 2017, 11, 4825-4831. [CrossRef] [PubMed]

87. Armbrüster, M.; Schlögl, R.; Grin, Y. Intermetallic compounds in heterogeneous catalysis—A quickly developing field. Sci. Technol. Adv. Mater. 2014, 15, 034803. [CrossRef] [PubMed] 
88. Varela, A.S.; Schlaup, C.; Jovanov, Z.P.; Malacrida, P.; Horch, S.; Stephens, I.E.L.; Chorkendorff, I. CO $_{2}$ Electroreduction on Well-Defined Bimetallic Surfaces: Cu Overlayers on Pt(111) and Pt(211). J. Phys. Chem. C 2013, 117, 20500-20508. [CrossRef]

89. Jovanov, Z.P.; Hansen, H.A.; Varela, A.S.; Malacrida, P.; Peterson, A.A.; Nørskov, J.K.; Stephens, I.E.; Chorkendorff, I. Opportunities and challenges in the electrocatalysis of $\mathrm{CO}_{2}$ and $\mathrm{CO}$ reduction using bifunctional surfaces: A theoretical and experimental study of Au-Cd alloys. J. Catal. 2016, 343, 215-231. [CrossRef]

90. Clark, E.L.; Hahn, C.; Jaramillo, T.F.; Bell, A.T. Electrochemical $\mathrm{CO}_{2}$ Reduction over Compressively Strained CuAg Surface Alloys with Enhanced Multi-Carbon Oxygenate Selectivity. J. Am. Chem. Soc. 2017, 139, 15848-15857. [CrossRef]

91. Peterson, A.A.; Nørskov, J.K. Activity Descriptors for $\mathrm{CO}_{2}$ Electroreduction to Methane on Transition-Metal Catalysts. J. Phys. Chem. Lett. 2012, 3, 251-258. [CrossRef]

92. Leonard, M.E.; Orella, M.J.; Aiello, N.; Román-Leshkov, Y.; Forner-Cuenca, A.; Brushett, F.R. Editors' Choice-Flooded by Success: On the Role of Electrode Wettability in $\mathrm{CO}_{2}$ Electrolyzers that Generate Liquid Products. J. Electrochem. Soc. 2020, $167,124521$. [CrossRef]

93. Leonard, M.E.; Clarke, L.E.; Forner-Cuenca, A.; Brown, S.M.; Brushett, F.R. Investigating Electrode Flooding in a Flowing Electrolyte, Gas-Fed Carbon Dioxide Electrolyzer. ChemSusChem 2020, 13, 400-411. [CrossRef]

94. Dinh, C.-T.; Burdyny, T.; Kibria, G.; Seifitokaldani, A.; Gabardo, C.M.; De Arquer, F.P.G.; Kiani, A.; Edwards, J.P.; De Luna, P.; Bushuyev, O.S.; et al. $\mathrm{CO}_{2}$ electroreduction to ethylene via hydroxide-mediated copper catalysis at an abrupt interface. Science 2018, 360, 783-787. [CrossRef]

95. Burchardt, T. An evaluation of electrocatalytic activity and stability for air electrodes. J. Power Sources 2004, 135, 192-197. [CrossRef]

96. Bidault, F.; Brett, D.; Middleton, P.; Brandon, N. Review of gas diffusion cathodes for alkaline fuel cells. J. Power Sources 2009, 187, 39-48. [CrossRef]

97. Jeanty, P.; Scherer, C.; Magori, E.; Wiesner-Fleischer, K.; Hinrichsen, O.; Fleischer, M. Upscaling and continuous operation of electrochemical $\mathrm{CO}_{2}$ to $\mathrm{CO}$ conversion in aqueous solutions on silver gas diffusion electrodes. J. CO2 Util. 2018, $24,454-462$. [CrossRef]

98. Albo, J.; Perfecto-Irigaray, M.; Beobide, G.; Irabien, A. Cu/Bi metal-organic framework-based systems for an enhanced electrochemical transformation of $\mathrm{CO}_{2}$ to alcohols. J. CO2 Util. 2019, 33, 157-165. [CrossRef]

99. Bienen, F.; Kopljar, D.; Löwe, A.; Geiger, S.; Wagner, N.; Klemm, E.; Friedrich, K.A. Revealing Mechanistic Processes in GasDiffusion Electrodes During $\mathrm{CO}_{2}$ Reduction via Impedance Spectroscopy. ACS Sustain. Chem. Eng. 2020, 8, 13759-13768. [CrossRef]

100. Zhang, X.; Guo, S.-X.; Gandionco, K.A.; Bond, A.M.; Zhang, J. Electrocatalytic carbon dioxide reduction: From fundamental principles to catalyst design. Mater. Today Adv. 2020, 7, 100074. [CrossRef]

101. Karamad, M.; Tripkovic, V.; Rossmeisl, J. Intermetallic Alloys as CO Electroreduction Catalysts-Role of Isolated Active Sites. ACS Catal. 2014, 4, 2268-2273. [CrossRef]

102. Gu, J.; Hsu, C.-S.; Bai, L.; Chen, H.M.; Hu, X. Atomically dispersed $\mathrm{Fe}^{3+}$ sites catalyze efficient $\mathrm{CO}_{2}$ electroreduction to $\mathrm{CO}$. Science 2019, 364, 1091-1094. [CrossRef] [PubMed]

103. Bellini, M.; Folliero, M.G.; Evangelisti, C.; He, Q.; Hu, Y.; Pagliaro, M.V.; Oberhauser, W.; Marchionni, A.; Filippi, J.; Miller, H.A.; et al. A Gold-Palladium Nanoparticle Alloy Catalyst for CO Production from $\mathrm{CO}_{2}$ Electroreduction. Energy Technol. 2019, 7, 1800859. [CrossRef]

104. Ma, X.; Li, Z.; Achenie, L.E.K.; Xin, H. Machine-Learning-Augmented Chemisorption Model for $\mathrm{CO}_{2}$ Electroreduction Catalyst Screening. J. Phys. Chem. Lett. 2015, 6, 3528-3533. [CrossRef]

105. Zheng, X.; Ji, Y.; Tang, J.; Wang, J.; Liu, B.; Steinrück, H.-G.; Lim, K.; Li, Y.; Toney, M.F.; Chan, K.; et al. Theory-guided Sn/Cu alloying for efficient $\mathrm{CO}_{2}$ electroreduction at low overpotentials. Nat. Catal. 2019, 2, 55-61. [CrossRef]

106. Bernal, M.; Bagger, A.; Scholten, F.; Sinev, I.; Bergmann, A.; Ahmadi, M.; Rossmeisl, J.; Cuenya, B.R. CO 2 electroreduction on copper-cobalt nanoparticles: Size and composition effect. Nano Energy 2018, 53, 27-36. [CrossRef]

107. Zhu, W.; Tackett, B.M.; Chen, J.G.; Jiao, F. Bimetallic Electrocatalysts for $\mathrm{CO}_{2}$ Reduction. Top. Curr. Chem. 2018, 376, 105-125. [CrossRef]

108. Lee, S.Y.; Jung, H.; Kim, N.-K.; Oh, H.-S.; Min, B.K.; Hwang, Y.J. Mixed Copper States in Anodized Cu Electrocatalyst for Stable and Selective Ethylene Production from $\mathrm{CO}_{2}$ Reduction. J. Am. Chem. Soc. 2018, 140, 8681-8689. [CrossRef] [PubMed]

109. Han, X.; Thoi, V.S. Non-Innocent Role of Porous Carbon Towards Enhancing C2-3 Products in Electroreduction of Carbon Dioxide. ACS Appl. Mater. Interfaces 2020, 12, 45929-45935. [CrossRef]

110. Li, Q.; Zhang, X.; Zhou, X.; Li, Q.; Wang, H.; Yi, J.; Liu, Y.; Zhang, J. Simply and effectively electrodepositing Bi-MWCNT-COOH composite on $\mathrm{Cu}$ electrode for efficient electrocatalytic $\mathrm{CO}_{2}$ reduction to produce HCOOH. J. CO2 Util. 2020, 37, 106-112. [CrossRef]

111. Liu, T.; Ali, S.; Lian, Z.; Li, B.; Su, D.S. $\mathrm{CO}_{2}$ electoreduction reaction on heteroatom-doped carbon cathode materials. J. Mater. Chem. A 2017, 5, 21596-21603. [CrossRef]

112. Vasileff, A.; Zheng, Y.; Qiao, S.Z. Carbon Solving Carbon's Problems: Recent Progress of Nanostructured Carbon-Based Catalysts for the Electrochemical Reduction of $\mathrm{CO}_{2}$. Adv. Energy Mater. 2017, 7, 1700759. [CrossRef]

113. Klinkova, A.; De Luna, P.; Dinh, C.-T.; Voznyy, O.; Larin, E.M.; Kumacheva, E.; Sargent, E.H. Rational Design of Efficient Palladium Catalysts for Electroreduction of Carbon Dioxide to Formate. ACS Catal. 2016, 6, 8115-8120. [CrossRef] 
114. Malhotra, M.; Sharma, R.; Sanduja, M.; Kumar, R.; Jain, J.; Deep, A. Synthesis, characterization and evaluation of mannich bases as potent antifungal and hydrogen peroxide scavenging agents. Acta Pol. Pharm. Drug Res. 2012, 69, 355-361.

115. Hegenberger, E.; Wu, N.L.; Phillips, J. Evidence of strong interaction between iron particles and an activated carbon support. J. Phys. Chem. 1987, 91, 5067-5071. [CrossRef]

116. Sharma, S.; Pollet, B.G. Support materials for PEMFC and DMFC electrocatalysts-A review. J. Power Sources 2012, 208, 96-119. [CrossRef]

117. Bittencourt, C.; Hecq, M.; Felten, A.; Pireaux, J.J.; Ghijsen, J.; Felicissimo, M.P.; Rudolf, P.; Drube, W.; Ke, X.; Van Tendeloo, G. Platinum-carbon nanotube interaction. Chem. Phys. Lett. 2008, 462, 260-264. [CrossRef]

118. Yuan, J.; Yang, M.-P.; Zhi, W.-Y.; Wang, H.; Wang, H.; Lu, J.-X. Efficient electrochemical reduction of $\mathrm{CO}_{2}$ to ethanol on Cu nanoparticles decorated on N-doped graphene oxide catalysts. J. CO2 Util. 2019, 33, 452-460. [CrossRef]

119. Liang, Z.-Q.; Zhuang, T.-T.; Seifitokaldani, A.; Li, J.; Huang, C.-W.; Tan, C.-S.; Li, Y.; De Luna, P.; Dinh, C.T.; Hu, Y.; et al. Copperon-nitride enhances the stable electrosynthesis of multi-carbon products from $\mathrm{CO}_{2}$. Nat. Commun. 2018, 9, 3828. [CrossRef] [PubMed]

120. Lewera, A.; Timperman, L.; Roguska, A.; Alonso-Vante, N. Metal-Support Interactions between Nanosized Pt and Metal Oxides $\left(\mathrm{WO}_{3}\right.$ and $\left.\mathrm{TiO}_{2}\right)$ Studied Using X-ray Photoelectron Spectroscopy. J. Phys. Chem. C 2011, 115, 20153-20159. [CrossRef]

121. Wen, G.; Ren, B.; Park, M.G.; Yang, J.; Dou, H.; Zhang, Z.; Deng, Y.; Bai, Z.; Yang, L.; Gostick, J.; et al. Ternary Sn-Ti-O Electrocatalyst Boosts the Stability and Energy Efficiency of $\mathrm{CO}_{2}$ Reduction. Angew. Chem. Int. Ed. 2020, 59, 12860-12867. [CrossRef]

122. Pan, Y.; Lin, R.; Chen, Y.; Liu, S.; Zhu, W.; Cao, X.; Chen, W.; Wu, K.; Cheong, W.-C.; Wang, Y.; et al. Design of Single-Atom Co-N5 Catalytic Site: A Robust Electrocatalyst for $\mathrm{CO}_{2}$ Reduction with Nearly $100 \%$ CO Selectivity and Remarkable Stability. J. Am. Chem. Soc. 2018, 140, 4218-4221. [CrossRef] [PubMed]

123. Jackson, M.N.; Oh, S.; Kaminsky, C.J.; Chu, S.B.; Zhang, G.; Miller, J.T.; Surendranath, Y. Strong Electronic Coupling of Molecular Sites to Graphitic Electrodes via Pyrazine Conjugation. J. Am. Chem. Soc. 2018, 140, 1004-1010. [CrossRef] [PubMed]

124. Yang, H.; Lin, Q.; Zhang, C.; Yu, X.; Cheng, Z.; Li, G.; Hu, Q.; Ren, X.; Zhang, Q.; Liu, J.; et al. Carbon dioxide electroreduction on single-atom nickel decorated carbon membranes with industry compatible current densities. Nat. Commun. 2020, 11, 593. [CrossRef]

125. Zhang, Y.-Y.; Li, J.-X.; Ding, L.-L.; Liu, L.; Wang, S.-M.; Han, Z.-B. Palladium Nanoparticles Encapsulated in the MIL-101-Catalyzed One-Pot Reaction of Alcohol Oxidation and Aldimine Condensation. Inorg. Chem. 2018, 57, 13586-13593. [CrossRef] [PubMed]

126. Matsuda, S.; Tamura, S.; Yamanaka, S.; Niitsuma, Y.; Sone, Y.; Umeda, M. Minimization of Pt-electrocatalyst deactivation in $\mathrm{CO}_{2}$ reduction using a polymer electrolyte cell. React. Chem. Eng. 2020, 5, 1064-1070. [CrossRef]

127. Lu, X.; Yu, T.; Wang, H.; Qian, L.; Lei, P. Electrochemical Fabrication and Reactivation of Nanoporous Gold with Abundant Surface Steps for $\mathrm{CO}_{2}$ Reduction. ACS Catal. 2020, 10, 8860-8869. [CrossRef]

128. Hou, Y.; Bolat, S.; Bornet, A.; Romanyuk, Y.E.; Guo, H.; Moreno-García, P.; Montiel, I.Z.; Lai, Z.; Müller, U.; Grozovski, V.; et al. Photonic Curing: Activation and Stabilization of Metal Membrane Catalysts (MMCs) for the Electrochemical Reduction of $\mathrm{CO}_{2}$. ACS Catal. 2019, 9, 9518-9529. [CrossRef] 